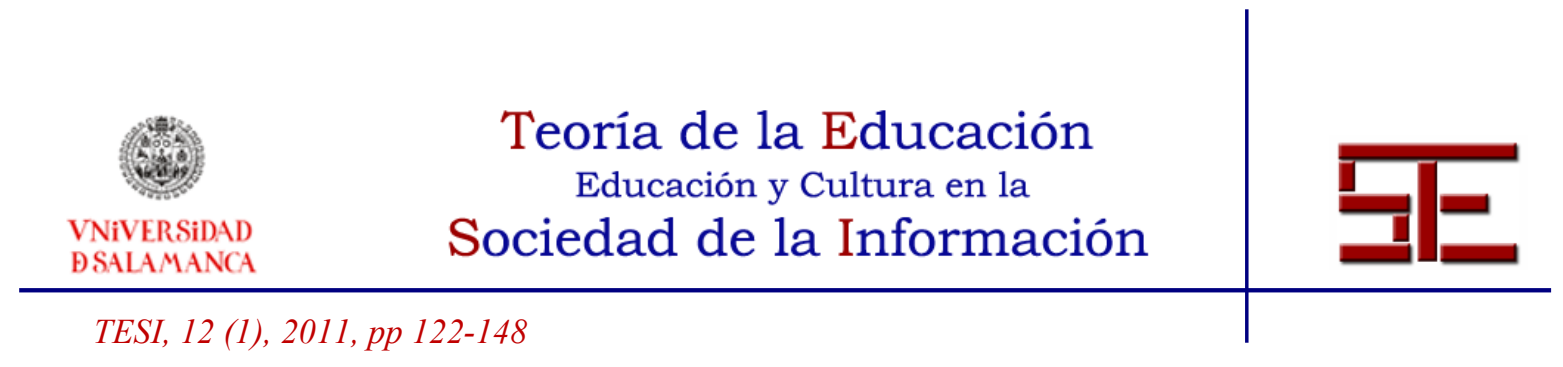

\title{
LA MUJER Y LA INVESTIGACIÓN EN TECNOLOGÍA EDUCATIVA. ANÁLISIS DE SU PRESENCIA EN LA AUTORÍA DE ARTÍCULOS CIENTÍFICOS
}

Resumen: La figura de la mujer en el mundo de la tecnología ha ido creciendo poco a poco en las últimas décadas, reflejándose esta circunstancia en las publicaciones derivadas de sus trabajos tanto teóricos como investigadores. El presente artículo muestra la presencia del género femenino en la publicación de artículos realizados en la revista Píxel-Bit, Revista de Medios y Educación, a lo largo de sus 38 números de edición.

Para la realización del mismo se ha empleado un sistema categorial, previamente elaborado y validado por expertos relacionados con las Tecnologías de la Información y la Comunicación y Metodología de Investigación. Con él, fueron codificados la totalidad de los artículos publicados. Realizándose a continuación un análisis descriptivo: univariante y relacional.

Los principales resultados indican una constante presencia femenina en la autoría de los artículos, que abordan formatos de publicación tanto de reflexión como de investigación. Destacando el porcentaje de artículos de investigación realizados sobre la Aplicación de las TIC en la Universidad, encontrándose a continuación la formación del profesorado y la teleformación/e-learning.

Palabras clave: tecnologías de la información y la comunicación; mujer; producción científica; revista.

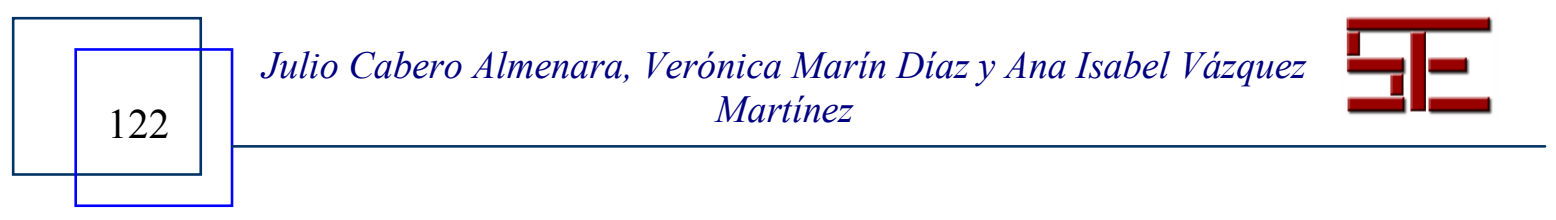




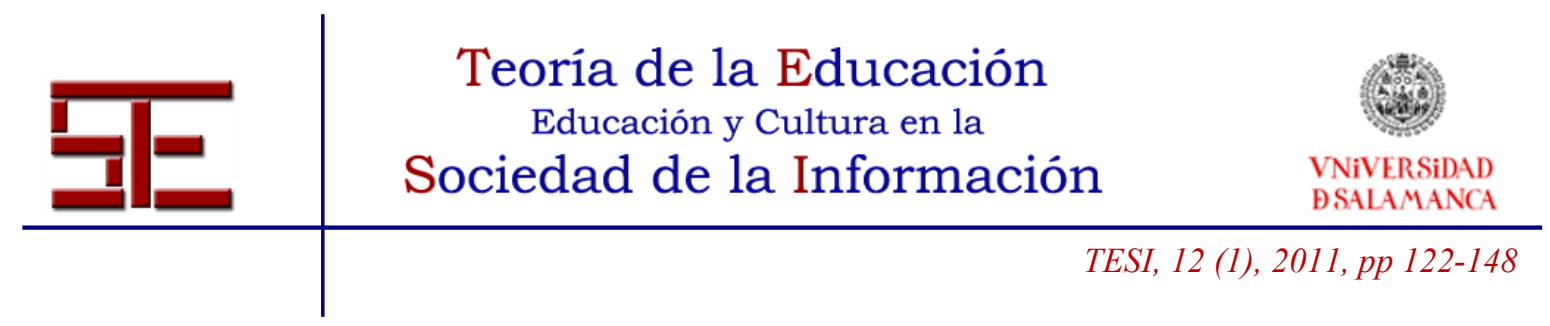

\title{
WOMEN AND RESEARCH IN EDUCATIONAL TECHNOLOGY. ANALYSIS OF ITS PRESENCE IN THE AUTHOR OF SCIENTIFIC PAPERS
}

\begin{abstract}
The role of women in the academic field of Technology has gradually increased in the last decades. Proof of this argument is the publication of research and theoretical work carried out by women. This paper acknowledges the presence of women in published papers in the journal Píxel-Bit, Revista de Medios de Comunicación, throughout its 38 numbers.
\end{abstract}

To this aim, we have employed a categorical system, previously designed and validated by experts in ICT and Research Methodology. This system was used to encode the already published papers.

Then, we conducted a descriptive analysis: monovariant and relational. The analysis of results shows a constant presence of female authors in reflection and research papers. We have also found out that there is a high percentage of women-written papers dealing with ICT use in higher education contexts, followed by teacher training and e-learning.

Keywords: information technology and communication; women; scientific production; magazine.

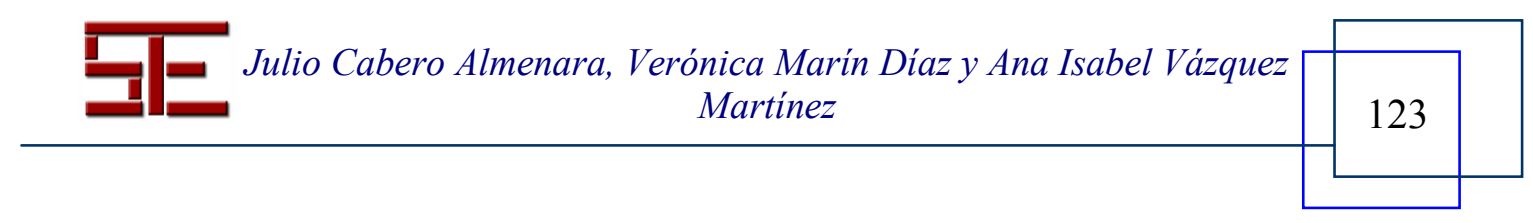




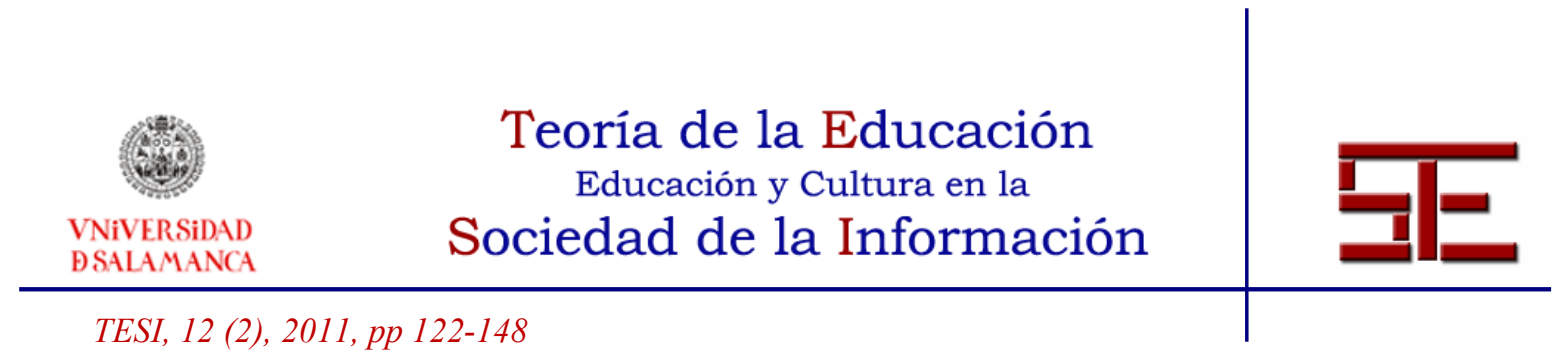

\section{LA MUJER Y LA INVESTIGACIÓN EN TECNOLOGÍA EDUCATIVA. ANÁLISIS DE SU PRESENCIA EN LA AUTORÍA DE ARTÍCULOS CIENTÍFICOS}

Fecha de recepción: 21/04/2011; fecha de aceptación: 16/06/2011; fecha de publicación: 27/07/2011

Julio Cabero Almenara

cabero@us.es

Universidad de Sevilla

Verónica Marín Díaz

vmarin@uco.es

Universidad de Córdoba

Ana Isabel Vázquez Martínez

aisabel@us.es

Universidad de Sevilla

\section{1.- UNAS REFERENCIAS INICIALES: LAS MUJERES Y LAS TECNOLOGÍAS}

Entendemos que es conveniente comenzar asumiendo que uno de los argumentos centrales que se han manejado en la relación al binomio tecnologías-género es que aquéllas son un enclave de dominio masculino y un rasgo definitorio de masculinidad (Castaño, 2005). Con las Tecnologías de la Información y la Comunicación está sucediendo lo mismo que sucedió en el pasado con la sociedad, que estaba, supuestamente, soportada sobre la masculinidad y, en consecuencia, está de nuevo sirviendo como elemento de discriminación entre hombres y mujeres. Como sostiene Cabero (2004) dentro de la denominada "brecha digital", nos encontramos con diferentes tipos de ellas, siendo una de las mismas la del género. Lo verdaderamente importante de esta brecha digital es que en la Sociedad de la Información las tecnologías se están convirtiendo en elemento de desarrollo y potenciación, de forma que la falta de un conocimiento así como de su utilización con cierto grado de soltura, se está convirtiendo no solamente en un elemento que dificulta el acceso a la información sino también en un mecanismo de exclusión y marginación social. Por otra parte como señala Wajcman (2006):

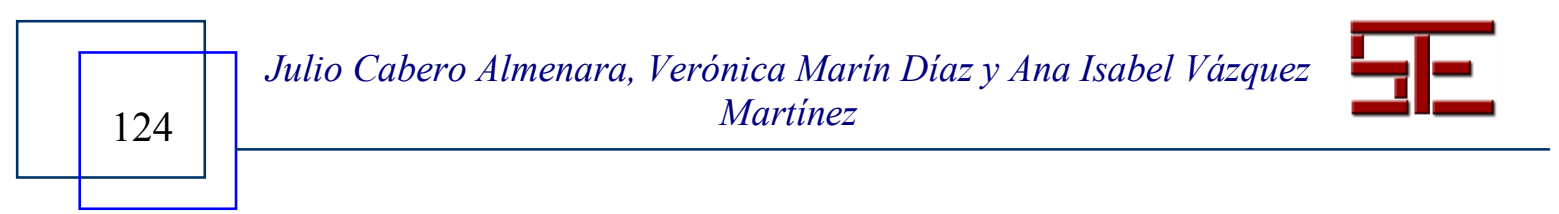




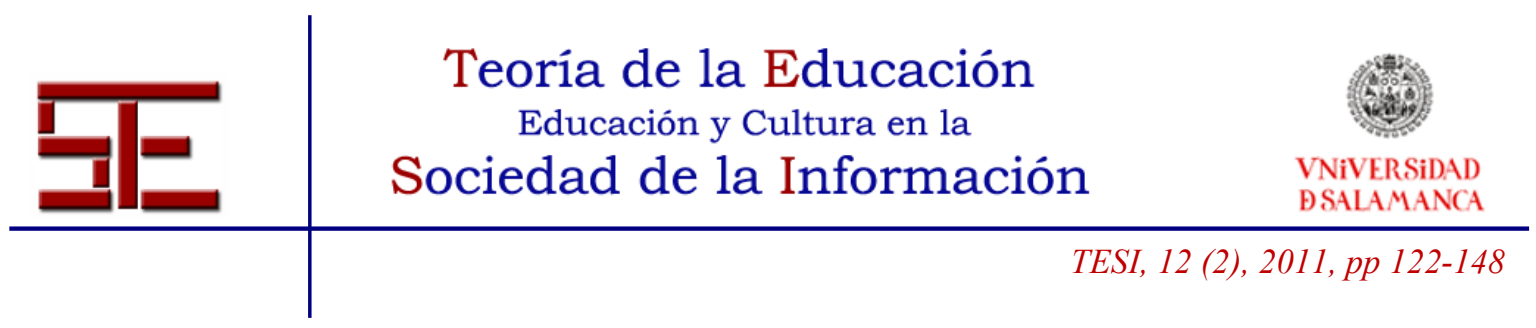

\begin{abstract}
Mientras que los comentaristas más optimistas de la revolución digital prometen libertad, empoderamiento y riqueza, raras veces demuestran tener conciencia laguna de las relaciones entre tecnología y género. Da la sensación de que ni siquiera se paran a pensar en el hecho de que los varones siguen dominando los campos científicos y tecnológicos así, como sus instituciones, Dominar la tecnología más puntera significa tener una mayor implicación en el futuro, cunado no ejercer un poder mayor sobre él (23-24).
\end{abstract}

Por ello creemos que es uno de los motivos que nos debe llevar a reclamar la realización de estudios sobre las posibles relaciones que se pueden establecer entre las Tecnologías de la Información y la Comunicación y las mujeres. En el libro publicado por Barroso y Cabero (2010) sobre investigación en Tecnología Educativa, se propone como una de las líneas futuras de investigación la referida a los aspectos relativos al género y a la utilización e incorporación de las TIC en los procesos de enseñanza-aprendizaje. Como señalan Vázquez, Ángulo y Rodríguez (2007):

... el binomio "género y nuevas tecnologías" ha sido abordado en muy contadas ocasiones y su tratamiento ha estado remitido al campo del aprendizaje de una materia curricular a través de las nuevas tecnologías o de los cursos de informática misma, en el mejor de los casos. Queremos decir que el género como tema de estudio en educación tiene una importante tradición de análisis, pero que en lo relativo a la tecnología de la información, nos encontramos, desgraciadamente, en un momento inicial (32).

Esta circunstancia es, precisamente, la que hemos perseguido en nuestro trabajo, aportar nuevas relaciones en este binomio, en concreto, ver la relación entre las mujeres y las tecnologías desde la óptica de su implicación en la producción de trabajos científicos acerca de la aplicación y utilización de las mismas en el contexto educativo. Y ello también en el sentido, que como señala Wajcman (2006, 26-27): "La escuela, las asociaciones juveniles, la familia y los medios de comunicación transmiten significados y valores que identifican la masculinidad con las máquinas y las aptitudes para la tecnología"; y por analogía pensamos que si la presencia como autoras de artículos es mínima e irrelevante.

Creemos, además, que algo debe suceder en esta temática sobre la brecha digital de género, cuando desde la propia Administración se asume la existencia ésta relativa al género, tratando de paliarla desde el Plan Avanza (http://www.planavanza.es/Paginas/Inicio.aspx), el cual dispone de una línea específica denominada "Igualdad de Género en la Sociedad de la Información".

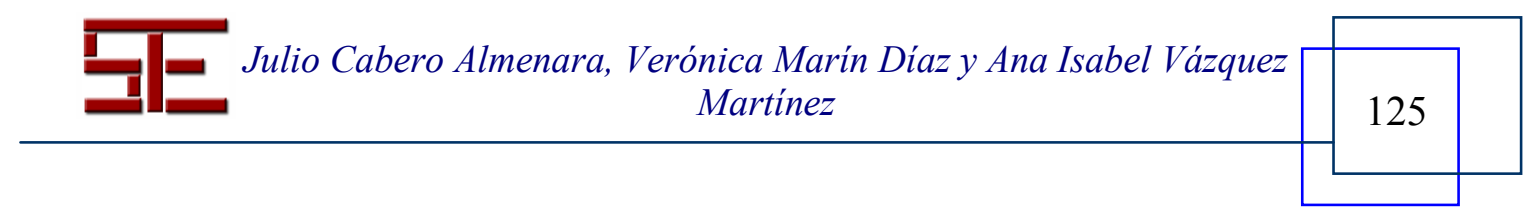




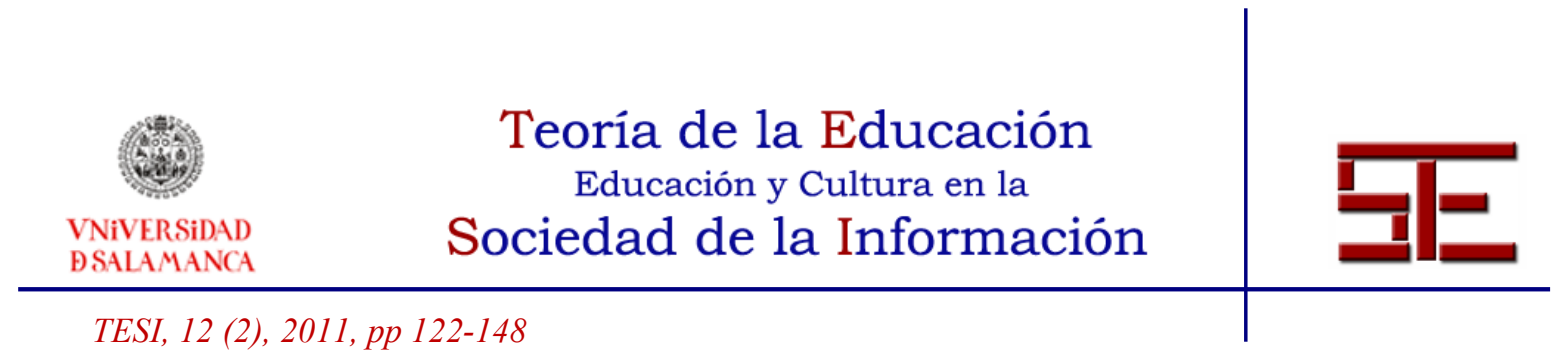

Al analizar la relación existente entre las mujeres y los hombres respecto a las tecnologías, lo primero que debemos considerar es que viene influenciada por diferentes variables de distinta naturaleza, así el Instituto Nacional de Estadística (INE) en el estudio realizado en 2009, nos llama la atención respecto a cómo la brecha digital de género es inversamente proporcional al tipo de estudio; es decir, a nivel universitario suele producirse menos que a nivel de estudios primarios, donde si nos encontramos con una fuerte diferencia entre los hombres y las mujeres.

Los estudios que se han desarrollado sobre las TIC y las mujeres se han llevado a cabo desde distintas perspectivas, unas centradas en la búsqueda de divergencias entre los hombres y las mujeres, otras en el análisis de posibles diferencias sobre utilización y usos específicos entre los hombres y las mujeres. A continuación vamos a ofrecer algunos de los resultados que estos estudios nos han aportado.

Creemos necesario indicar que las posibles diferencias que podemos encontrar respecto a las posibles diferencias del uso de las TIC en función del género se deben desde el principio a que tradicionalmente las herramientas informáticas en el contexto escolar han estado asociadas al rol masculino, lo mismo que determinadas carreras de ciencias tenían una mayor presencia masculina. En esta asociación han repercutido diferentes tipos de variables, como pueden ser el tiempo de uso de los niños en los ordenadores en las escuelas sea superior al de las niñas (Plomp, 1996; Gargallo, Suárez \& Belloch, 2003); la exclusión de estas prácticas a las niñas respecto a los niños (Terlon, 1996). Ello sin lugar a dudas, ha influido en posiciones de acercamiento diferentes de los hombres y las mujeres en un futuro hacia las TIC, tanto en general como en particular.

Resultan llamativos los datos aportados en la investigación llevada a cabo por FletcherFlinn y Suddendorf (1996a y b; 1997, citado por Urbina, 2002), quienes realizaron tres estudios con el fin de examinar las actitudes hacia el ordenador y el efecto de visiones específicas del género sobre la conducta exploratoria de los niños de educación infantil, quienes fueron entrevistados sobre sus actitudes antes y después de una sesión de trabajo con un cuento interactivo (storybook). Los resultados indicaron que estos niños tienen una concienciación hacia el uso del ordenador muy elevada, manteniendo los varones más estereotipos relacionados con el género. En los otros dos estudios se utilizó un cuestionario para evaluar las actitudes hacia el ordenador de estudiantes de mayor edad.

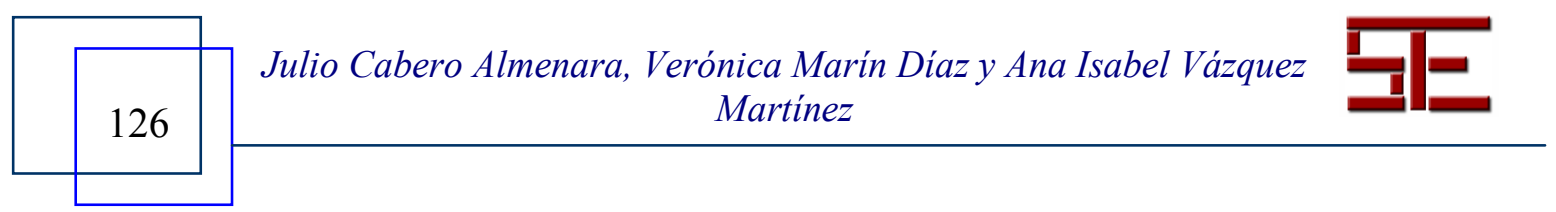




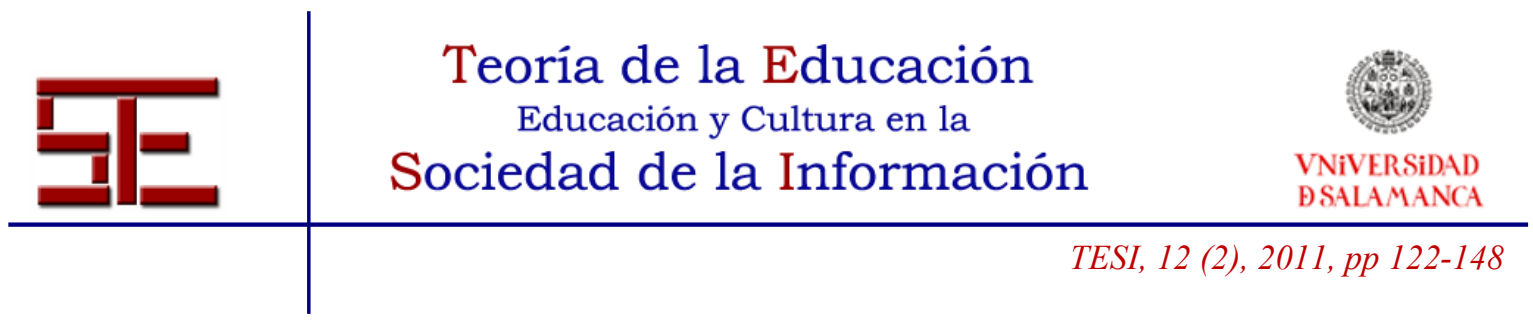

Esta forma diferente de acercamiento los medios desde el mundo educativo podemos verla también en las revistas de informática y en la representación que se hace de las mujeres en estas revistas. Vázquez y otros (2007) presentan en su trabajo la investigación realizada en su momento por Carles y Ortega (1999), que señalan como, en las imágenes publicitarias de estas revistas, las mujeres aparecen mayoritariamente como reclamo erótico (un $67,38 \%$ frente a un $0,4 \%$ de varones) y los varones como usuarios $(99,6 \%$ frente a un 32,64\%). En el texto, la representación de las mujeres es aún inferior, como era de esperar (un 20,08\% frente al 75,92\% de varones); además su papel no pasa de ser el de usuarias, mientras ellos aparecen, con mucha frecuencia, como expertos. Estos análisis no son una cuestión baladí, pues la representación de la publicidad es la que prefigura a aquello que puede existir.

Esta perspectiva tradicional está repercutiendo para que diferentes investigaciones nos aporten con toda claridad que el conocimiento sobre las TIC que muestran las mujeres es menor que el que poseen los hombres. Tales diferencias, incluso, se han llegado a encontrar en el sistema educativo, donde el conocimiento mostrado por los profesores es superior al expuesto por las profesoras (García Valcárcel, 2005; Almerich; Suárez; Orellana; Belloch; Bo \& Gastaldo 2004).

Por lo que se refiere a medios concretos, un grupo de investigaciones han encontrado diferencias significativas entre los hombres y las mujeres respecto a la frecuencia de uso que hacen de tecnologías concretas; así por ejemplo diferentes investigaciones (Orellana; Almerich; Belloch \& Díaz, 2004; Duart y otros, 2008) han encontrado que el uso de Internet es mayor en el caso de los hombres que en las mujeres.

Ahora bien lo importante no es sólo que exista una diferencia respecto a la frecuencia de utilización de Internet, sino que lo que es más importante, por lo menos desde nuestro punto de vista, lo hacen de manera diferente. Así, Hernández Jorge, Acosta Jorge, Rodríguez Gutierrez, González García y Borges Díaz (2003) encontraron que mientras las mujeres tienden a realizar un mayor uso de Internet para el trabajo, los hombres lo hacen para la comunicación y el ocio. Sánchez y Aguaded (2001) señalan también que, aunque las mujeres utilizaban en menor frecuencia Internet, sí empleaban más el chat que los hombres. Por su parte, Ruiz y Sánchez (2010) encuentran que las coordinadoras de los centros TIC utilizan más recursos tales como los blog que los coordinadores. Becker (1986) en un estudio, ya tradicional, señala que las alumnas tienden a usar los ordenadores de modo diferente, focalizándose más en actividades como procesamiento

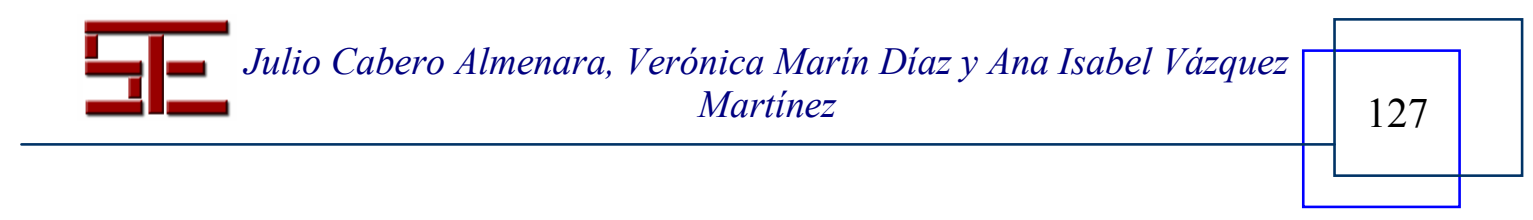




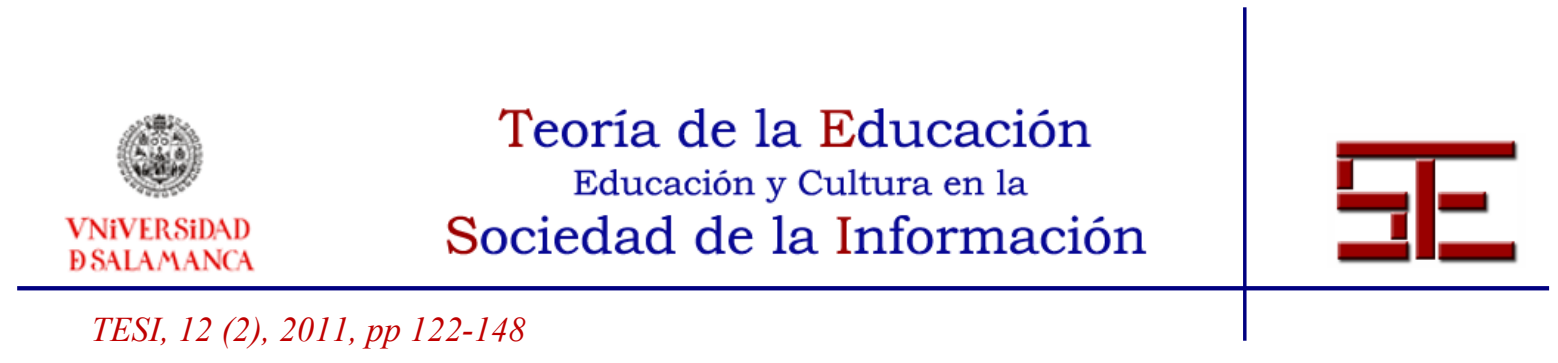

de palabras y trabajo en colaboración, mientras que los alumnos se orientan mucho más a los juegos y al trabajo competitivo.

En esta misma línea Volman y Van Eck (2001) analizaron las diferencias que existen en la utilización de las TIC en función del género. En la revisión de las diferentes investigaciones ponen de manifiesto cómo los usos que hacen los hombres y las mujeres son diferentes, cómo se aproximan a los medios de forma diferente y como muestran preferencias distintas por los tipos de programas.

En nuestro contexto, la investigación realizada por Vázquez y otros (2007), donde persiguen el objetivo de comprender el acceso, tratamiento, responsabilidad adquirida y uso de las tecnologías de la información por las mujeres, señala que:

Siempre realizan una utilización instrumental del ordenador en busca de una rentabilidad inmediata. Además, para las chicas y mujeres es un instrumento que facilita el trabajo y por tanto nunca un recurso para el ocio, así aunque hayan utilizado el ordenador en edades más tempranas, a partir de una determinada edad $(15,16$ años) se abandona y el ocio pasa a estar más ligado a las relaciones personales o actividades como la lectura, la música, etc.., ya que, como comentan, es para ellas más gratificante relacionarse con otros/as que permanecer solas manipulando una „máquinaee (38).

Sin embargo, también empezamos a encontrar diferentes estudios en los cuales las diferencias entre ambos géneros o son muy pequeñas o nada significativas. Sánchez (2011) ha realizado recientemente una investigación para ver si hay diferencias entre los coordinadores y coordinadoras de los centros TIC en la provincia de Málaga respecto a una serie de aspectos como son: a) "Si existen diferencias en la integración de las TIC en el currículo en función del género de la persona que coordina el proyecto"; b) "Si existen diferencias en la integración de las TIC en la actividad a nivel de centro en función del género de la persona que coordina el proyecto"; y c) "Si existen diferencias en la gestión (organización y mantenimiento) de los recursos TIC del centro en función del género de la persona que coordina el proyecto". Encontrando tras su investigación que no pudo rechazar ninguna de las hipótesis nulas formuladas, $\mathrm{y}$ por tanto no se encontraron diferencias significativas.

Cabero, Barroso y Llorente (2008), en el estudio realizado sobre las ponencias y comunicaciones presentadas a los diferentes congresos de Edutec, obtuvieron las siguientes conclusiones respecto a la variable género: a) Aunque los hombres han presentado más comunicaciones en solitario que las mujeres, la poca diferencia respecto

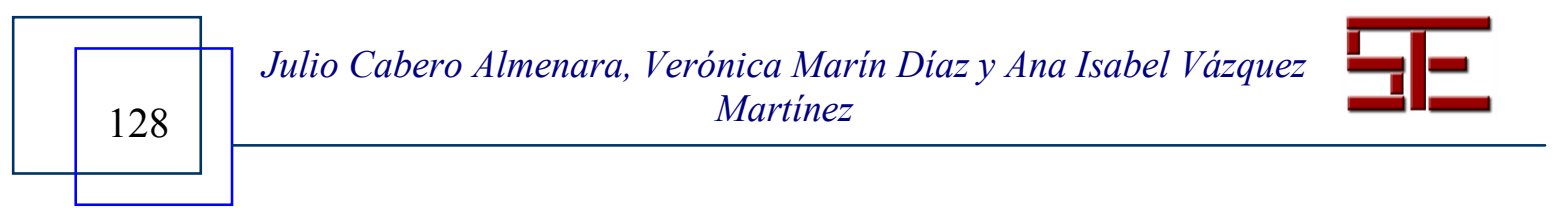




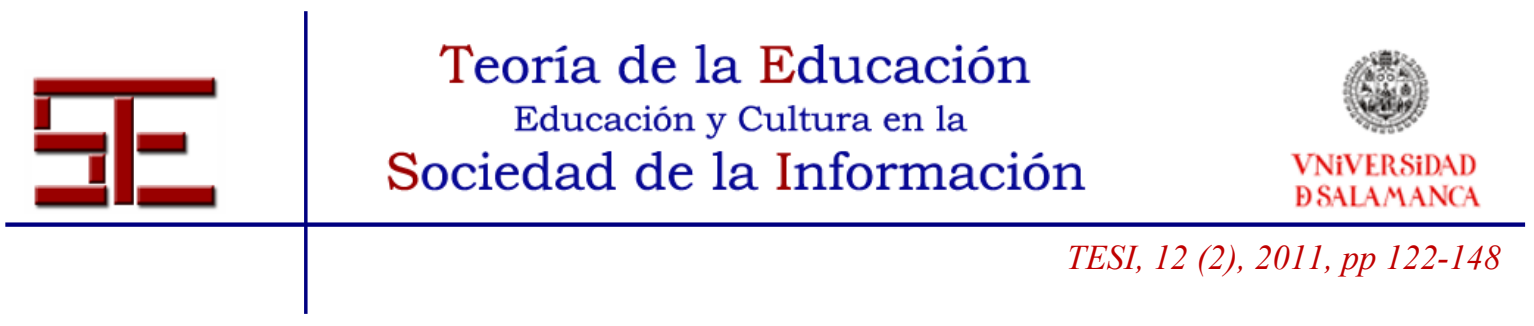

a las mujeres y el número de comunicaciones presentadas por equipos de carácter nos lleva a señalar que la variable género no se ha mostrado influyente en el volumen de comunicaciones presentadas. Tales diferencias no se encuentran de manera mayoritaria en las subtemáticas; y b) Por lo general no se han encontrado grandes diferencias en las temáticas tratadas y el género de los autores de las comunicaciones. Tales diferencias se dieron en una serie de temáticas, en el caso de los hombres en: "Medios de comunicación y educación", "Diseño de materiales", "Formación en entornos no formales" y "Usos de las TIC"; y de las mujeres: "Actitudes hacia los medios", "Evaluación de medios y materiales", "Medios de comunicación y educación" y "Organización de medios y materiales".

Recientemente, Ruiz y Sánchez (2010), al analizar si el género era un factor influyente en la integración de las TIC por parte de los coordinadores de TIC en los centros educativos, encuentran que no hay grandes diferencias al respecto, en relación a los proyectos puestos en funcionamiento en los centros educativos.

\section{2.- EL ESTUDIO REALIZADO}

Como hemos señalado anteriormente el estudio de la figura de la mujer dentro del mundo de las tecnologías de la información y la comunicación no es nuevo en nuestro panorama. Podemos hacer una retrospectiva de los estudios publicados sobre el tema por autores y organismos como Xie y Shauman (1998), Fox y Stephan (2001), Sax, Hagedorn, Arredondo y Dicrisi (2002), Mallow y Hake (2002), Romero Tena (2004), Agudo (2006), Anta Cebreros (2006), Arranz (2006), Fecyt (2006), García de Cortázar (2006), Viedma (2006), Castaño y González (2008), Abramo, D'Angelo y Caprasecca (2009), Sandström (2009), McGrath Cohoon, Nigai y Jofish Kaye (2010). Sin embargo, pocos son los estudios que se han centrado en conocer la presencia que las mismas han tenido como personas de producción científica, y menos aún en el ámbito de la "Tecnología Educativa" (TE) y las "Tecnologías de la Información y Comunicación" (TIC), y ello es precisamente lo que hemos querido abarcar en este trabajo, si bien es cierto que no con la pretensión de comenzar un debate sobre el tema, pero sí continuar con los análisis e investigaciones citadas desde el enfoque de la producción científica femenina en TIC.

En concreto, el objetivo general que perseguimos es conocer la presencia que las mujeres han tenido en la publicación de artículos científicos centrados en el ámbito de la TE y las TIC. Y para ello hemos realizado un análisis temático de los artículos

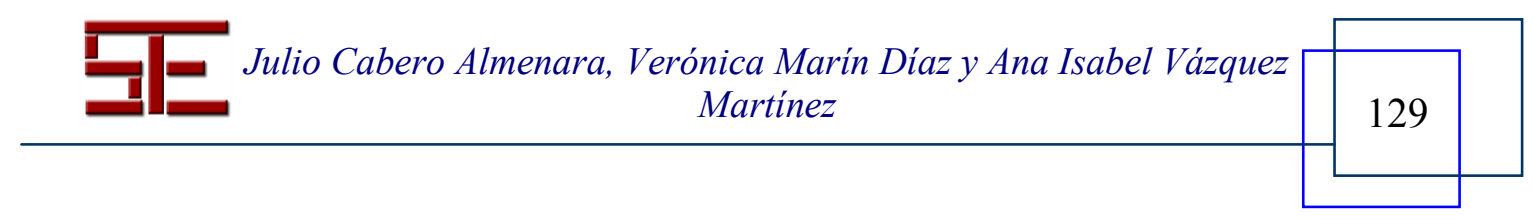




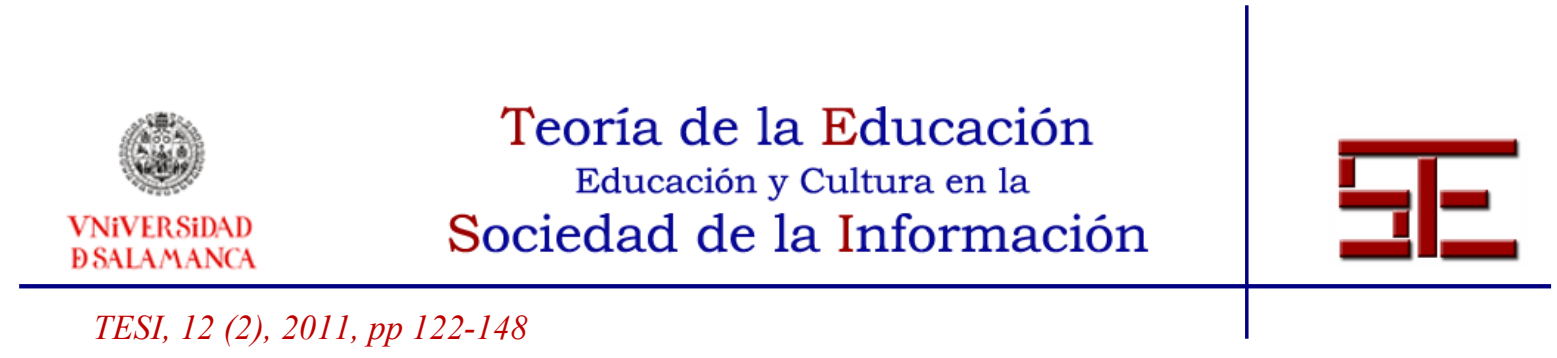

publicados en una de las revistas que en nuestro contexto científico español, se dedica monográficamente a la temática de los medios de enseñanza y las tecnologías de la información y comunicación, en concreto nos referimos a Píxel-Bit, Revista de Medios y Educación. Revista publicada desde 1994 por la Universidad de Sevilla a través de su Secretariado de Recursos Audiovisuales y Nuevas Tecnologías.

En concreto, los objetivos que perseguimos con nuestro trabajo son:

a) Identificar el número de artículos publicados en Píxel-Bit, Revista de Medios y Educación en cuya autoría existirá una mujer.

b) Conocer si la presencia de autoras ha sido constante a lo largo de los diferentes números publicados.

c) Y conocer las principales temáticas en las cuales se han centrado.

Como podemos observar nuestra pretensión no era llevar a cabo un estudio comparativo de autorías de artículos entre hombres y mujeres, sino más bien contrastar la presencia de estas últimas, validar una ficha de análisis y poner en funcionamiento una línea de investigación para conocer el acercamiento de las mujeres al terreno de las TIC, y más concretamente de su investigación y reflexión conceptual.

Señalar que nuestra investigación se enmarca dentro de lo que podríamos considerar análisis de contenido o documental. Con respecto a ello indicar que hemos seguido las siguientes fases y etapas: preanálisis, formación del sistema categorial, codificación, análisis e interpretación, y presentación del informe, que han recomendado diferentes autores (Bardin, 1986; Krippendorff, 1990; Cabero \& Loscertales, 1998; Barroso \& Cabero, 2010), que, consideramos, deben llevarse a cabo para su aplicación.

\section{1.- Material de análisis}

Como ya hemos señalado, el material de análisis ha sido Píxel-Bit. Revista de Medios y Educación, publicada por el Secretariado de Recursos Audiovisuales y Nuevas Tecnologías de la Universidad de Sevilla, que comenzó su andadura en 1994, y cuyo último número se publicó $\left(\mathrm{n}^{\circ} 38\right)$ en enero de 2011. La revista posee una versión electrónica (http://www.sav.us.es/pixelbit/), y se encuentra indizada en diferentes bases de datos y portales educativos: Iresie, Catálogo Latindex, Redalyc, Gale Cengage

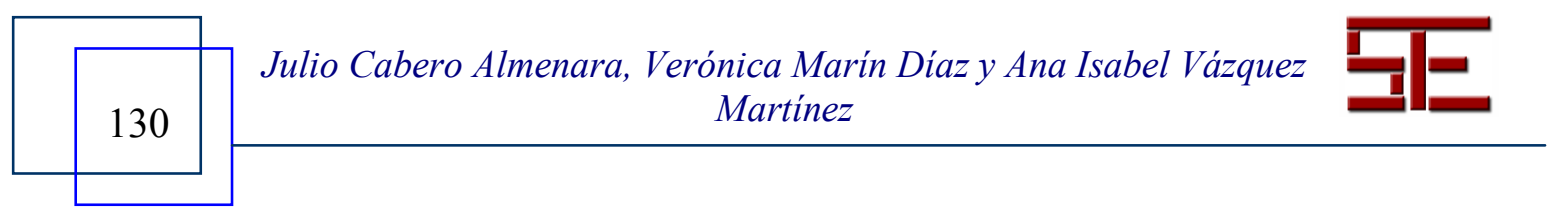




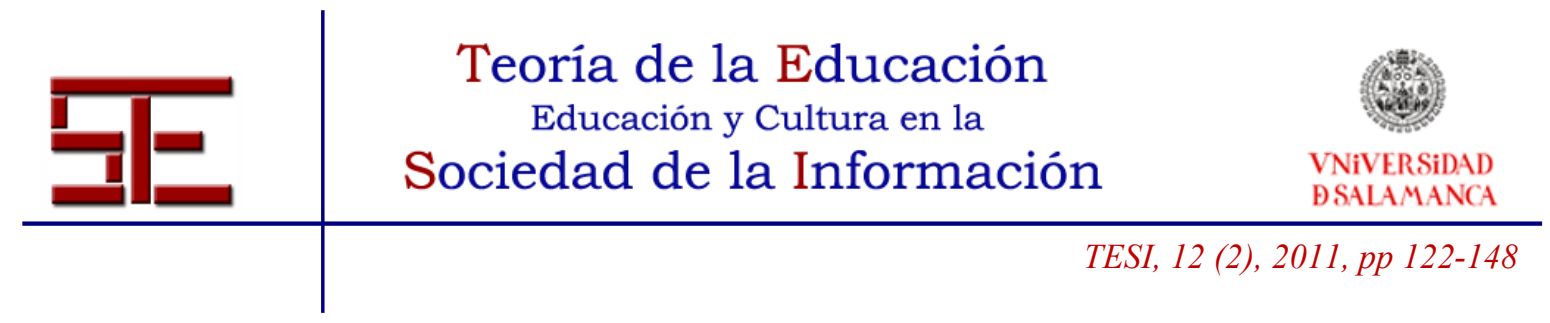

Learning, DICE, MIAR, Centro de Recursos de la OEI, ISOC, IN-RECS, Centro de Documentación del Observatorio de la Infancia en Andalucía...

El objeto de análisis ha sido cada artículo publicado, en concreto, se han analizado 373 artículos, que corresponden con los 18 años de publicación de Píxel-Bit.

\section{2.- Instrumento de análisis}

Para realizar este estudio retrospectivo hemos empleado el sistema de categorías utilizado por Cabero, Barroso y Llorente (2008), para llevar a cabo el análisis de los artículos publicados en la revista electrónica Edutec, con una única modificación, dado que se ha incluido la categoría "Otros" dentro del apartado temáticas.

Para comprobar la validez de dicha incorporación se sometió el sistema categorial a juicio de 6 expertos pertenecientes a las ramas de las Tecnologías de la Información y la Comunicación, y la Tecnología Educativa (4) y al de Metodología de Investigación (2) de las universidades de Córdoba, Huelva y Sevilla, dando como resultado el sistema categorial que a continuación se muestra.

Cuadro 1. Sistema categorial elaborado para la investigación

\begin{tabular}{|l|l|}
\hline \multicolumn{2}{|c|}{ Categoría } \\
\hline Género de autor/es & a) Hombre \\
& b) Mujer \\
& c) Mixto \\
& d) No posible su identificación \\
\hline Número de autores & a) Uno \\
& b) Dos \\
& c) Tres \\
& d) D) Más de tres \\
\hline Institución & a) Universitaria \\
& b) No Universitaria - Formal \\
& c) No Universitaria - no formal \\
\hline Actitudes hacia los medios & d) No posible su identificación. \\
\hline & a) Actitudes de los profesores hacia la tecnología \\
& b) Actitud del alumno hacia la tecnología \\
\hline
\end{tabular}

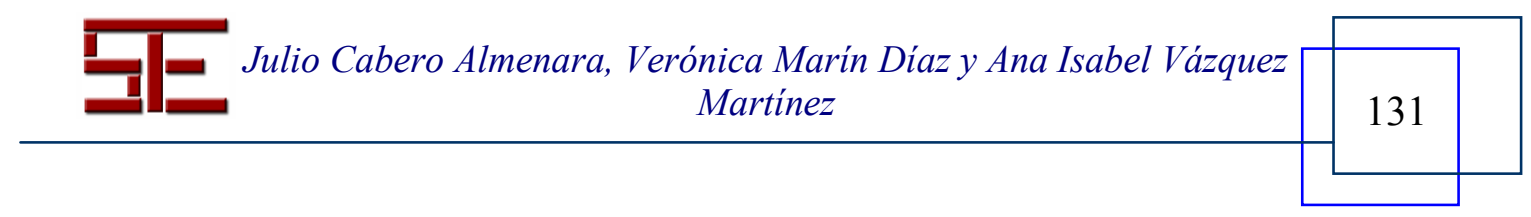




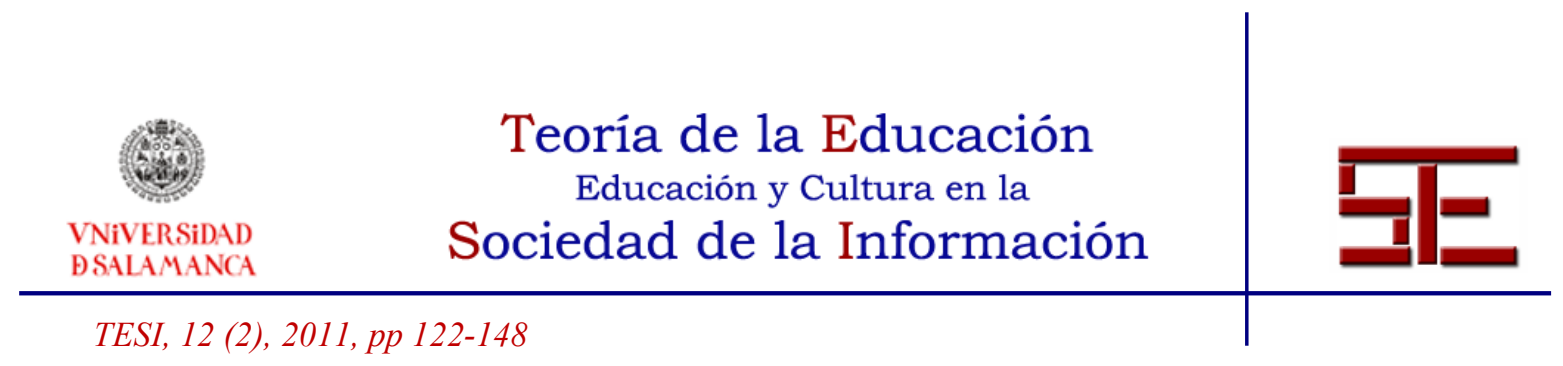

\begin{tabular}{|c|c|}
\hline Diseño de materiales & $\begin{array}{l}\text { f) Diseño de software informático } \\
\text { g) Vídeo aplicado a la enseñanza } \\
\text { h) Diseño de páginas web } \\
\text { i) Diseño de materiales para la red } \\
\text { j) Montajes audiovisuales/diaporamas }\end{array}$ \\
\hline $\begin{array}{llll}\begin{array}{l}\text { Evaluación } \\
\text { materiales }\end{array} & \text { de } & \text { medios } & y \\
\end{array}$ & $\begin{array}{l}\text { a) Evaluación de medios y materiales de } \\
\text { enseñanza }\end{array}$ \\
\hline Formación & $\begin{array}{l}\text { a) Formación del profesorado } \\
\text { b) Formación de los alumnos (alfabetización } \\
\text { audiovisual) }\end{array}$ \\
\hline $\begin{array}{l}\begin{array}{l}\text { Formación en } \\
\text { formales }\end{array} \\
\end{array}$ & $\begin{array}{l}\text { a) TIC y formación ocupacional } \\
\text { b) Las TIC y la orientación } \\
\text { c) Las TIC en la educación de adultos }\end{array}$ \\
\hline Formación on line & $\begin{array}{l}\text { a) Plataformas de teleformación } \\
\text { b) Las TIC aplicadas a la educación a distancia } \\
\text { c) Enseñanza asistida por ordenador } \\
\text { d) Teleformación/e-learning } \\
\text { e) Utilización educativa de la red } \\
\text { f) Tutoría on line/ asesoramiento on line }\end{array}$ \\
\hline $\begin{array}{l}\text { Medios de comunicación } y \\
\text { educación }\end{array}$ & $\begin{array}{l}\text { a) Prensa } \\
\text { b) Televisión } \\
\text { c) Cine } \\
\text { d) Medios de comunicación de masas } \\
\text { e) Videoconferencia } \\
\text { f) Radio educativa } \\
\text { g) Material impreso/ Hábitos lectores } \\
\text { h) Comic } \\
\text { i) Dibujos animados } \\
\text { j) Publicidad } \\
\text { k) Fotografía/diapositivas }\end{array}$ \\
\hline $\begin{array}{l}\text { Nuevas Tecnologías y Educación } \\
\text { Especial }\end{array}$ & $\begin{array}{l}\text { a) Utilización de las TIC para la educación } \\
\text { especial/diversidad }\end{array}$ \\
\hline $\begin{array}{l}\text { Organización de medios } \mathrm{y} \\
\text { materiales }\end{array}$ & $\begin{array}{l}\text { a) Centro de recursos } \\
\text { b) Las TIC y la organización/administración de } \\
\text { los Centros }\end{array}$ \\
\hline $\begin{array}{l}\text { Recursos para la educación y la } \\
\text { formación basada en las Nuevas }\end{array}$ & $\begin{array}{l}\text { a) Trabajo colaborativo en redes } \\
\text { b) Aplicación de las TIC en la Universidad }\end{array}$ \\
\hline
\end{tabular}

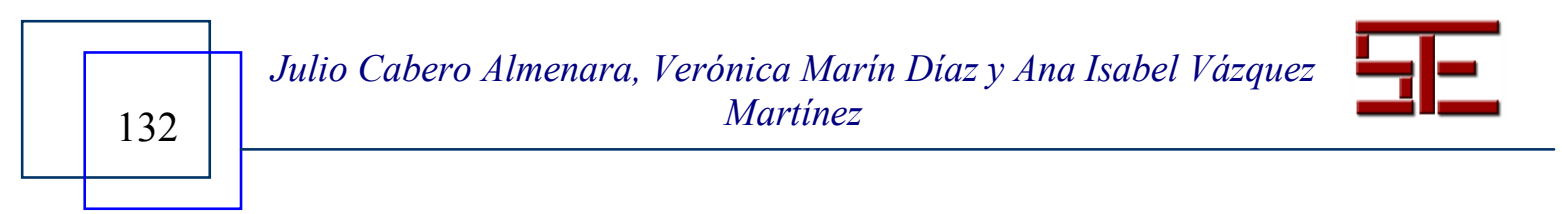




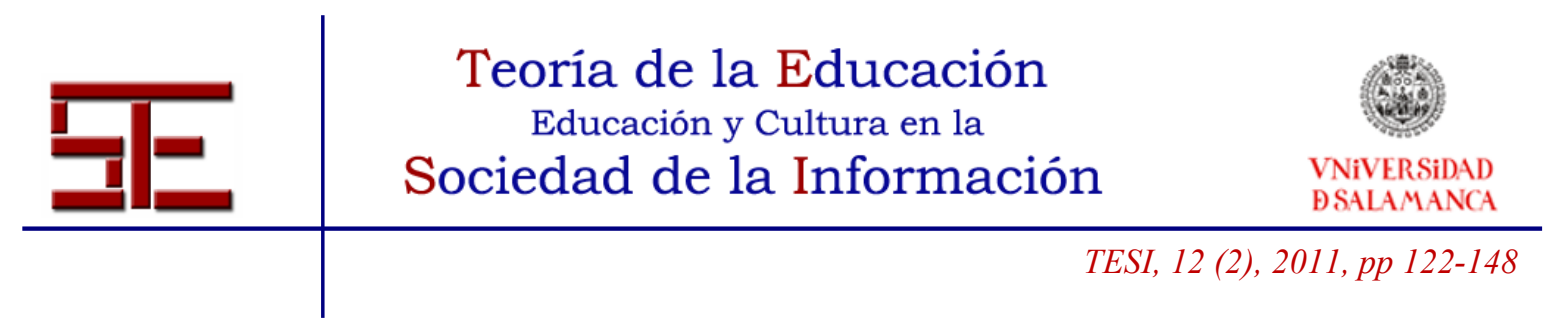

\begin{tabular}{|c|c|}
\hline Tecnologías & $\begin{array}{l}\text { c) Aplicación de las TIC en niveles no } \\
\text { universitarios } \\
\text { d) Experiencia de aplicaciones en contenidos } \\
\text { curriculares concretos } \\
\text { e) Experiencias educativas sobre audio/sonido } \\
\text { f) Programas institucionales de implantación de } \\
\text { las TIC } \\
\text { g) Reflexiones sobre la investigación en TIC y en } \\
\text { tecnología educativa } \\
\text { h) Aspectos cognitivos y TIC: estilos cognitivos, } \\
\text { estilos de aprendizaje } \\
\text { i) Planes de estudio referidos a las TIC }\end{array}$ \\
\hline $\begin{array}{l}\text { Sociedad de la información y la } \\
\text { comunicación }\end{array}$ & $\begin{array}{l}\text { a) Género y tecnología } \\
\text { b) Reflexiones generales sobre las TIC } \\
\text { (desigualdades, brecha digital, posibilidades, } \\
\text { limitaciones, aspectos filosóficos,...) } \\
\text { c) Sociedad de la información/ Sociedad del } \\
\text { conocimiento } \\
\text { d) TIC y violencia } \\
\text { e) Imágenes, estereotipos transmitidos por los } \\
\text { medios } \\
\text { f) Valores y TIC }\end{array}$ \\
\hline Usos de las TIC & $\begin{array}{l}\text { a) Informática aplicada a la educación } \\
\text { b) Multimedia/hipermedia/hipertexto } \\
\text { c) Inteligencia artificial } \\
\text { d) Teletrabajo } \\
\text { e) Videojuegos/ Juegos con ordenador } \\
\text { f) Comunidades virtuales } \\
\text { g) TIC y museos } \\
\text { h) Las TIC en las empresas } \\
\text { i) Utilización de herramientas de comunicación } \\
\text { jíncronas/asíncronas de Internet } \\
\text { j) La comunicación audiovisual }\end{array}$ \\
\hline
\end{tabular}

Señalar que los codificadores fueron las dos autoras del presente artículo, y que previamente antes de su aplicación se buscó un índice de concordancia entre las mismas. Para ello codificaron de forma independiente el primer número de la revista,

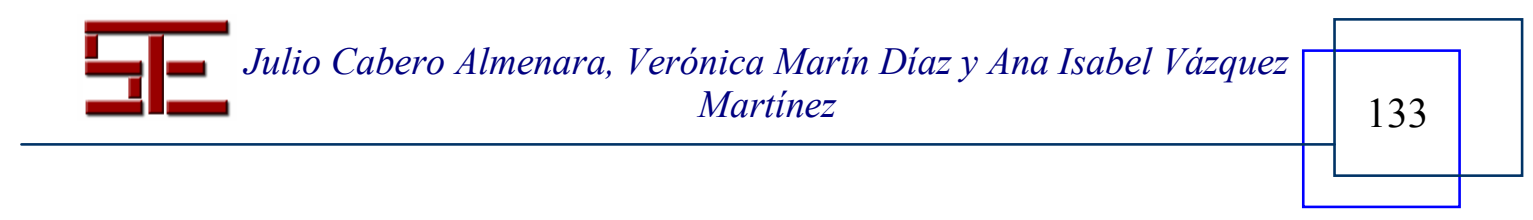




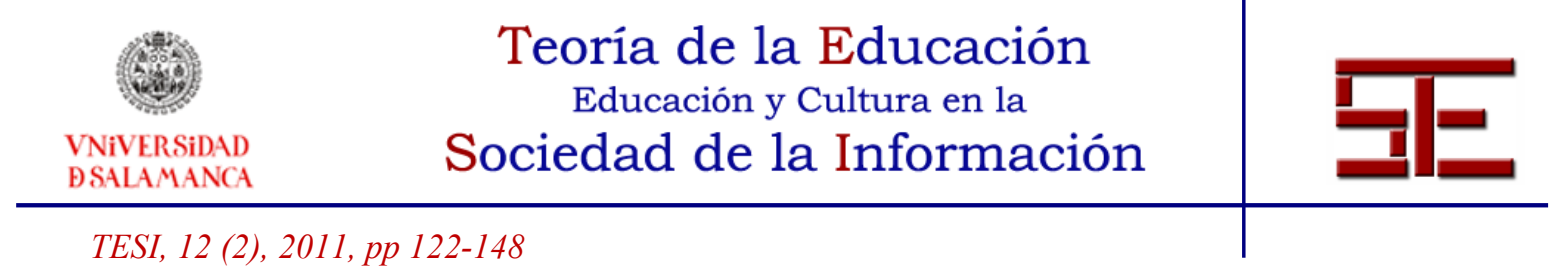

contrastando el tercer investigador el índice de acuerdo entre ambas codificaciones. Al mismo tiempo se celebró una reunión entre ambas codificadoras para resolver los desacuerdos, que fueron mínimos, encontrados.

De nuevo se siguió el mismo proceso con otro número de la revista. Una vez alcanzado el acuerdo total, se distribuyeron los números restantes entre las codificadoras.

Los datos recabados fueron analizados por el paquete estadístico SPSS en su versión 18, a través del cual se realizó un estudio descriptivo, en concreto dos pruebas, por un lado, el recuento de frecuencias y porcentajes y, por otro, el estudio de la contingencia años de publicación y número de autores mujeres y hombres, además de las de género femenino y temáticas sobre las que habían publicado.

\section{3.- RESULTADOS}

Nuestra primera intención era conocer si había presencia de autoras en los distintos números publicados por año. En la Tabla 1 presentamos los resultados alcanzados.

Tabla 1. Artículos publicados por años con presencia de autoras

\begin{tabular}{|c|c|c|}
\hline Año & Frecuencia & Porcentaje válido \\
\hline 1994 & 12 & 3,2 \\
1995 & 12 & 3,2 \\
1996 & 11 & 2,9 \\
1997 & 12 & 3,2 \\
1998 & 16 & 4,3 \\
1999 & 16 & 4,3 \\
2000 & 20 & 5,4 \\
2001 & 21 & 5,6 \\
2002 & 20 & 5,4 \\
2003 & 16 & 4,3 \\
2004 & 17 & 4,6 \\
2005 & 37 & 9,9 \\
2006 & 19 & 5,1 \\
\hline
\end{tabular}

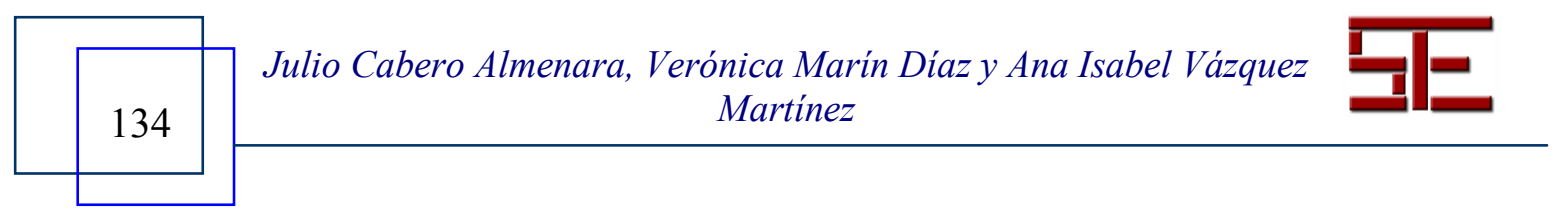




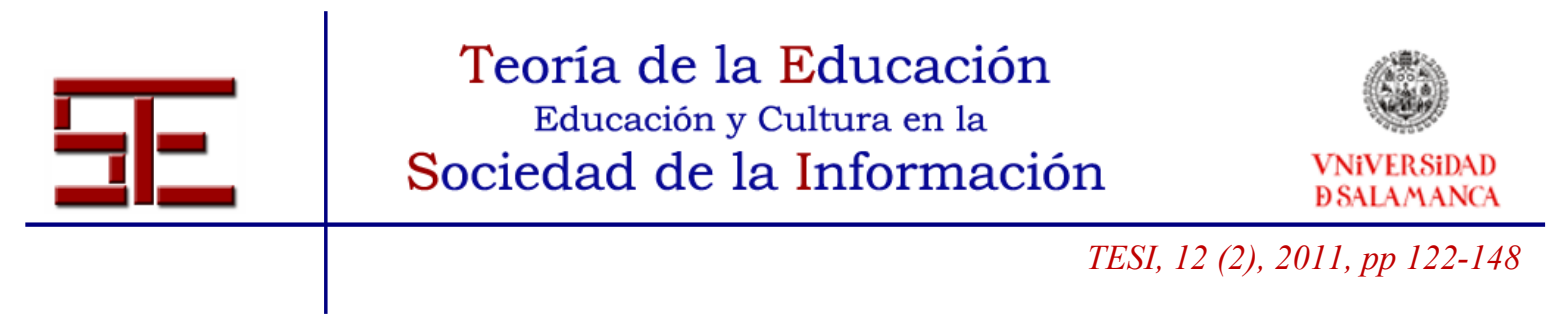

\begin{tabular}{|c|c|c|}
2007 & 22 & 5,9 \\
2008 & 23 & 6,2 \\
2009 & 31 & 8,3 \\
2010 & 32 & 8,6 \\
2011 & 36 & 9,7 \\
Total & 373 & 100,0 \\
\hline
\end{tabular}

Como podemos observar en la tabla anterior, el año en que más artículos se publicaron fue 2005, en el que aparecieron 37 artículos, seguido este del año 2010 con 36 artículos. Mientras que en 1996 salieron a la luz 11 artículos.

En el gráfico 1, se pueden observar los porcentajes de distribución en cada uno de los años publicados.

Gráfico 1. Porcentaje de artículos publicados desde 1994 hasta 2011

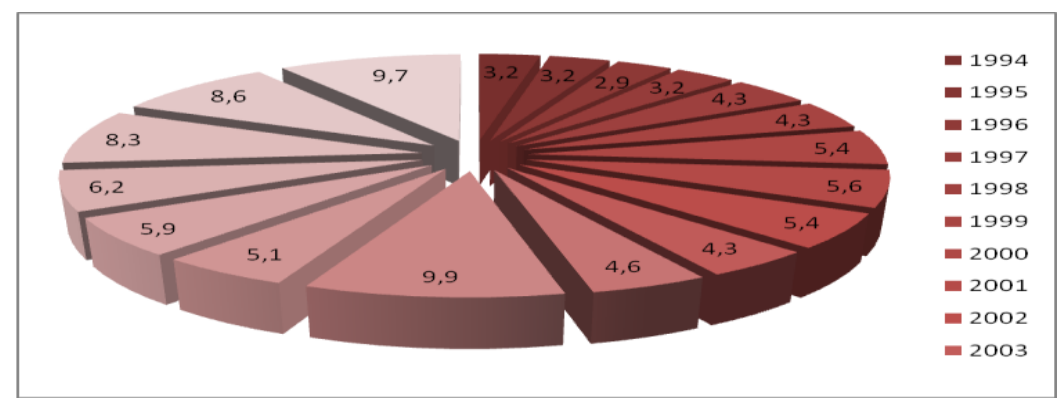

Nuestra siguiente intención fue conocer si existían entre estos artículos diferencias entre aquellos que eran de tipo reflexivo-conceptual, o eran investigaciones. Y al respecto nos encontramos una ligera diferencia a favor de los estudios de corte reflexivo-conceptual $(51,6 \%)$ frente a los de corte investigador $(48,4 \%)$.

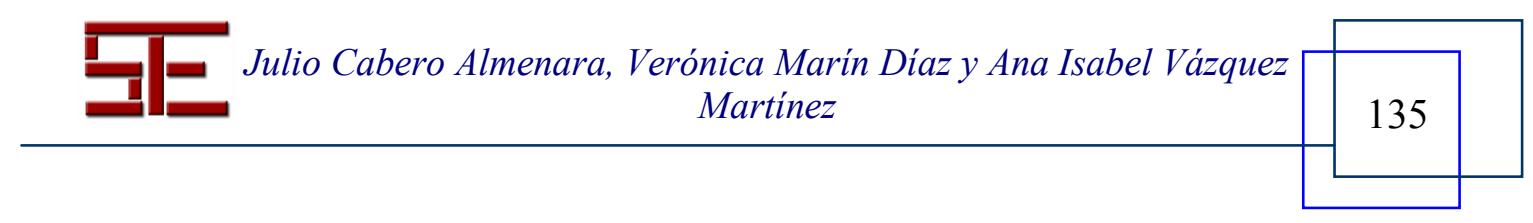




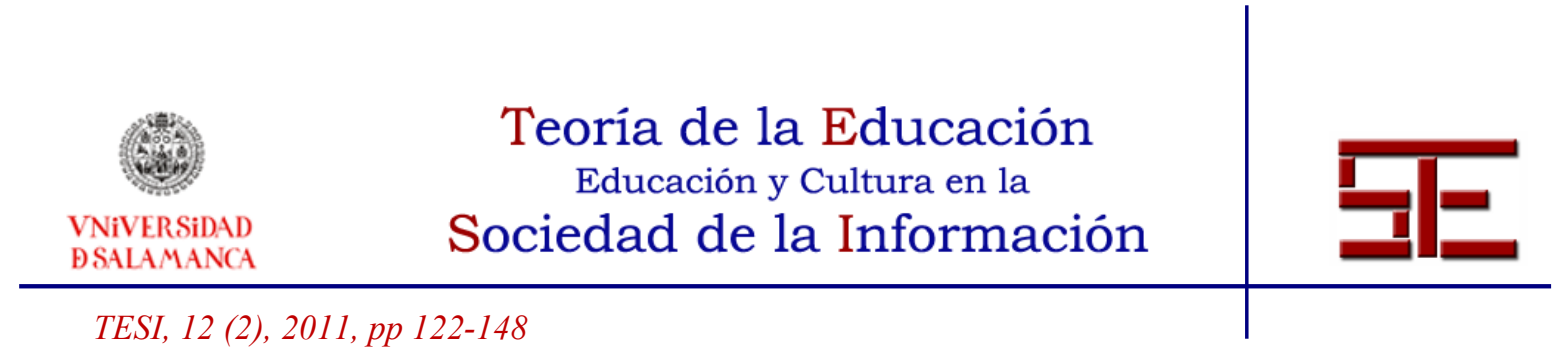

Gráfico 2: Distribución de los artículos por tipología y año

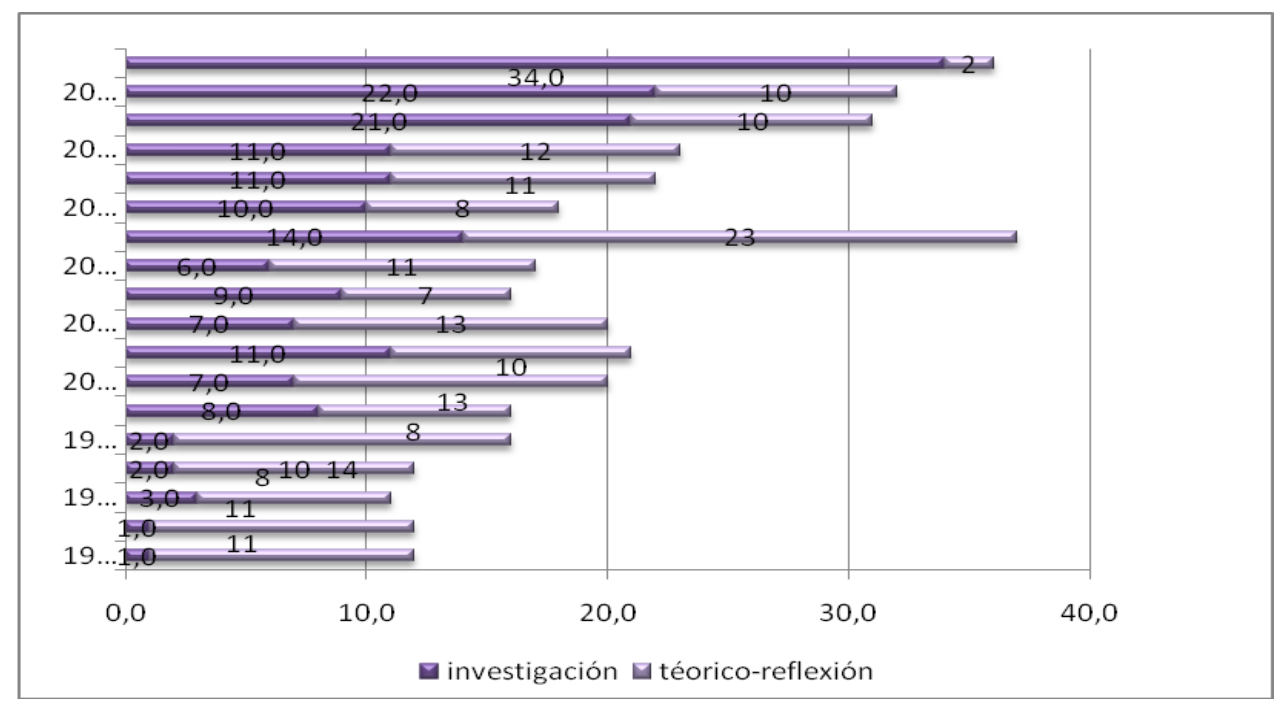

Como podemos observar en el Gráfico 2 los primeros 10 años de la revista se han publicado un alto número de artículos de corte teórico-reflexivo en detrimento a los de investigación; sin embargo, esta línea se ha ido modificando en su segunda década de vida, al ir a la par en cuanto a crecimiento. Sin embargo, a partir de 2009 se puede contemplar como los artículos publicados son de tipo investigador en detrimento de los de corte teórico. Por último, llamar la atención al lector como en el último número que ha visto la luz, el 38, sólo ha habido un artículo de tipo teórico-reflexivo de los 18 publicados.

Con respecto al número de autores que han participado en Píxel-Bit, podemos decir que el $44.5 \%$ de los artículos han sido firmados por un único autor, el $31.9 \%$ por dos autores, el $12.6 \%$ por tres autores, el $6.2 \%$ por 4 autores y el $4.8 \%$ por más de 4 autores. Así mismo, el $38.8 \%$ de los artículos es firmado únicamente por hombres, el 32.2\% por mujeres y el $29 \%$ por mujeres y hombres (ver Gráfico 3).

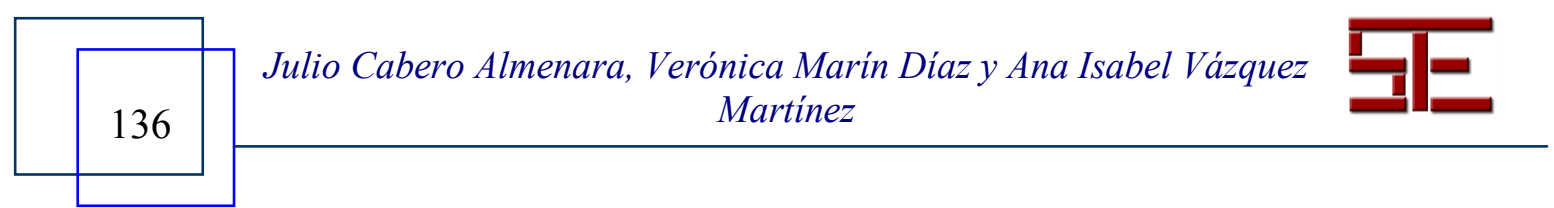




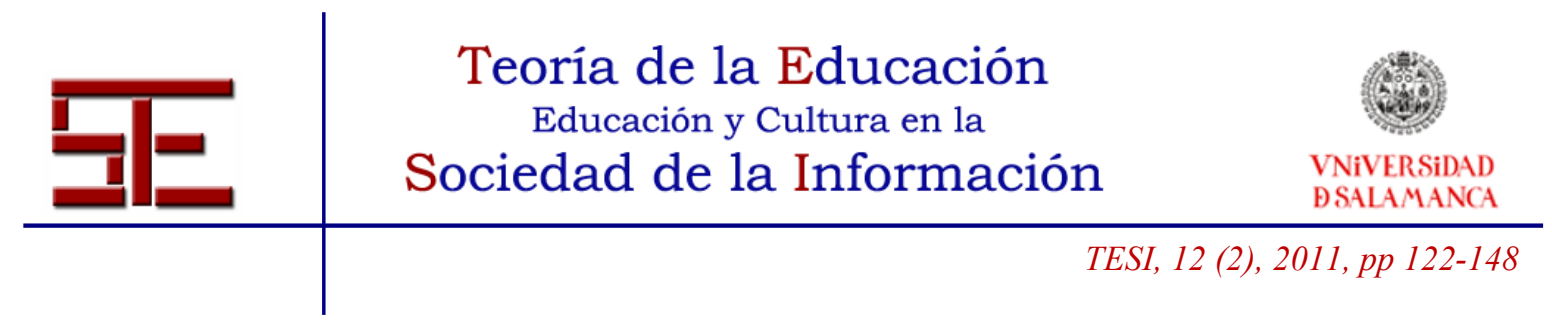

Gráfico 3. Distribución de hombres y mujeres en la autoría de los artículos

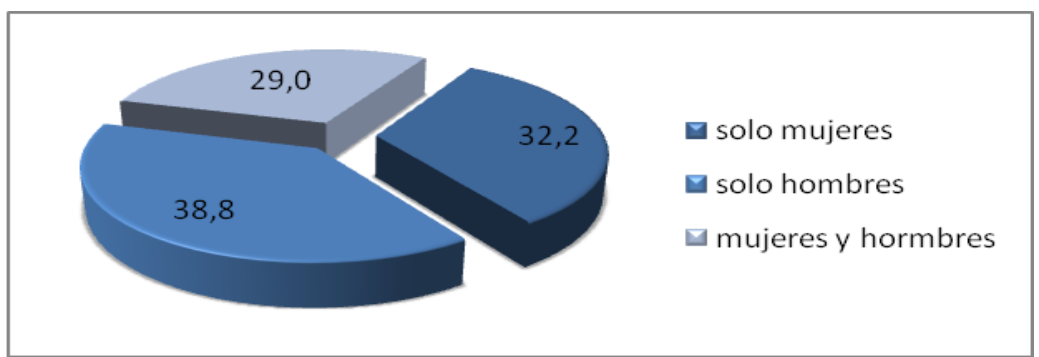

Tabla 2. Distribución de hombres y mujeres en la autoría de los artículos

\begin{tabular}{|c|c|c|c|}
\hline & & sólo mujeres & sólo hombres \\
\hline \multirow{18}{*}{ 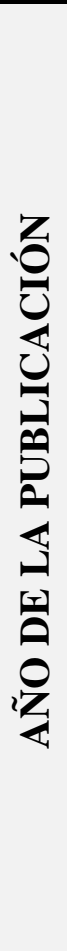 } & 1994 & 2 & 9 \\
\hline & 1995 & 4 & 5 \\
\hline & 1996 & 2 & 6 \\
\hline & 1997 & 4 & 5 \\
\hline & 1998 & 7 & 6 \\
\hline & 1999 & 6 & 8 \\
\hline & 2000 & 9 & 8 \\
\hline & 2001 & 8 & 8 \\
\hline & 2002 & 10 & 4 \\
\hline & 2003 & 5 & 5 \\
\hline & 2004 & 5 & 5 \\
\hline & 2005 & 12 & 15 \\
\hline & 2006 & 5 & 4 \\
\hline & 2007 & 7 & 8 \\
\hline & 2008 & 8 & 10 \\
\hline & 2009 & 6 & 13 \\
\hline & 2010 & 11 & 12 \\
\hline & 2011 & 7 & 11 \\
\hline
\end{tabular}

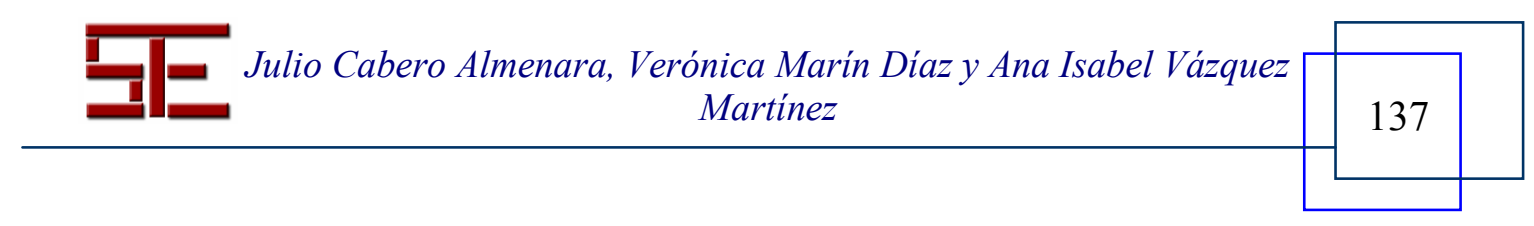




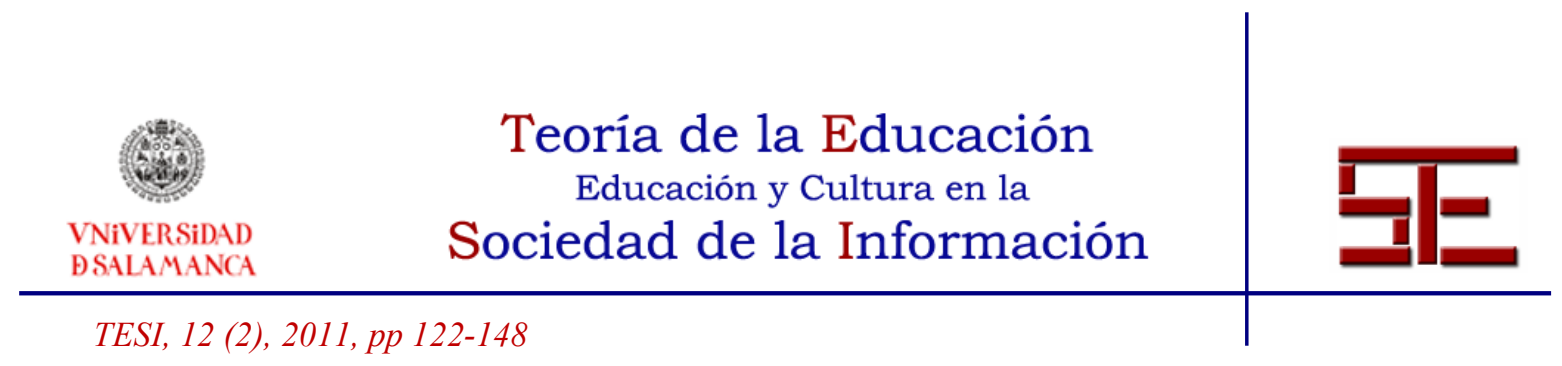

Atendiendo a su distribución por años, como podemos observar en la Tabla 2, la presencia de autoras ha sido bastante regular siendo en 2002, 2005 y 2011 los años en los que se han publicado más artículos firmados sólo por mujeres,-10, 12 y 11 respectivamente-, frente a los dos que se realizaron en 1994 y 1996.

Atendiendo al género comprobamos que de los 373 artículos publicados, 220 de ellos han sido firmados por una o varias mujeres, es significativo que en el $43.2 \%$ de ellos no encontramos presencia femenina, el 39.9\% tiene una única autora, el 12,3\% está firmado por dos mujeres, el $2.7 \%$ por 3 , el $1.4 \%$ de los artículos la autoría es de 4 mujeres y un $0.5 \%$ por más de 4 autoras (ver Gráfico 4 ).

Gráfico 4. Presencia de mujeres en la autoría de los artículos.

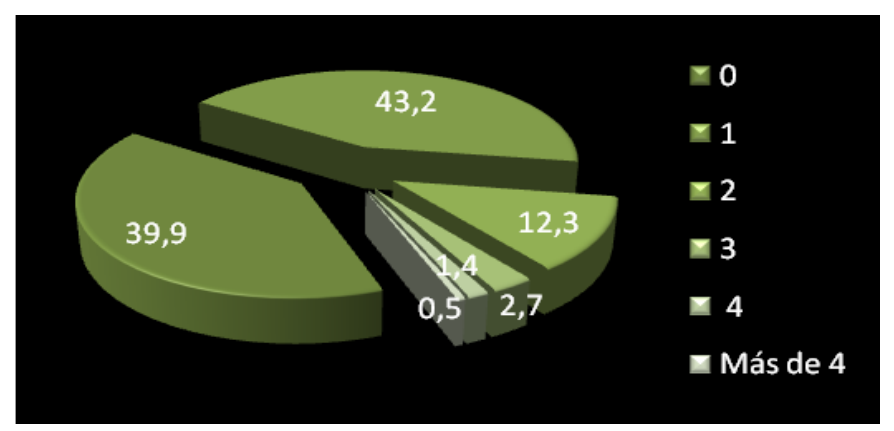

Fijando ahora nuestra atención en la dirección o coordinación de las publicaciones, tenemos que señalar, en primer lugar, que pocos son los artículos que nos hemos encontrado en esta línea, en concreto 8; y de ellos ninguno es coordinado o dirigido por una mujer.

En la mayoría de los casos sí ha sido posible, por el contrario, determinar la institución laboral de las autoras, siendo ésta, mayoritariamente, universitaria en un 93,8\%, seguida de no universitaria pero con carácter formal $(3,5 \%)$, no universitaria no formal $(1.3 \%) \mathrm{y}$ tan sólo en un $1.3 \%$ no ha sido posible identificar el lugar de procedencia laboral.

Como último aspecto descriptivo es interesante atender a la nacionalidad de las autoras. Conjugando el número de féminas con aquella variable, comprobamos que en el $88.4 \%$ de los artículos publicados por mujeres todas ellas son de nacionalidad española, frente

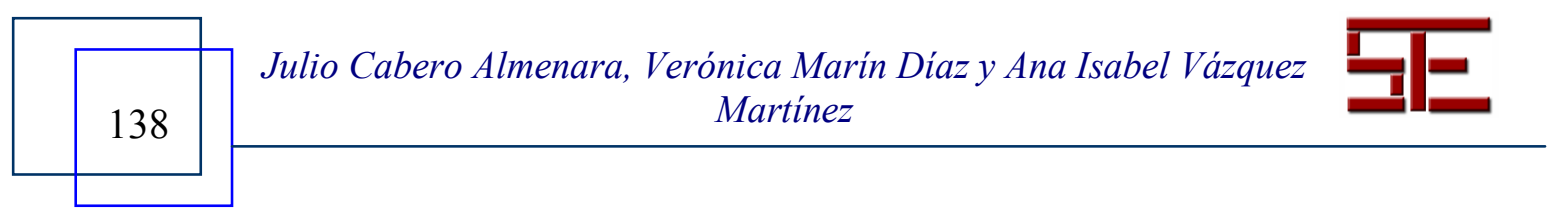




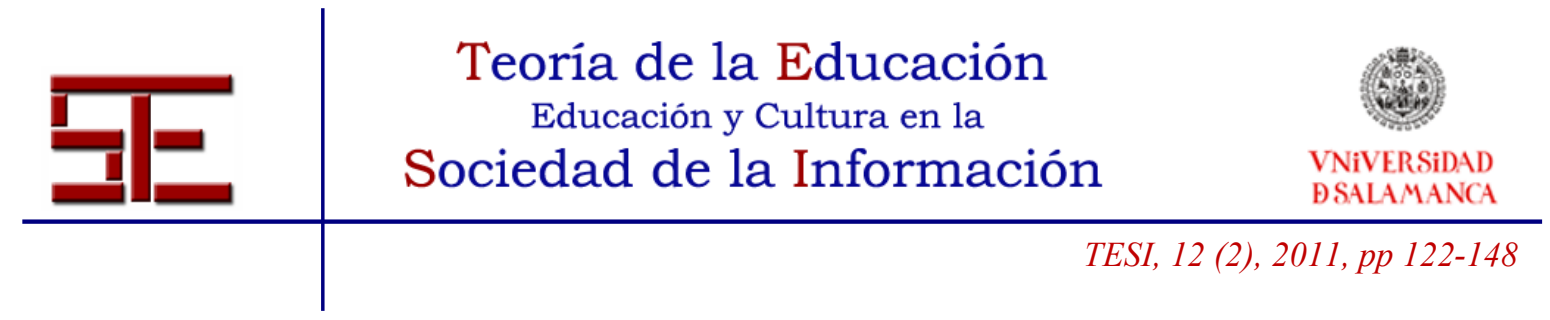

al $9.9 \%$ en el que las autoras que los firman son extranjeras, por último, encontramos que el $1.6 \%$ de los artículos está firmado por varias autoras tanto españolas como extranjeras.

Gráfico 5. Nacionalidad de las autoras

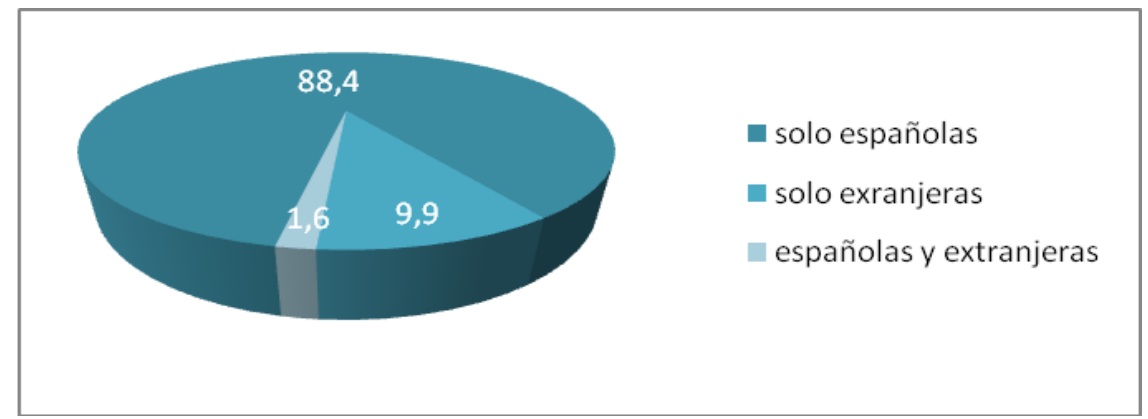

Gráfico 6. País de procedencia de las autoras

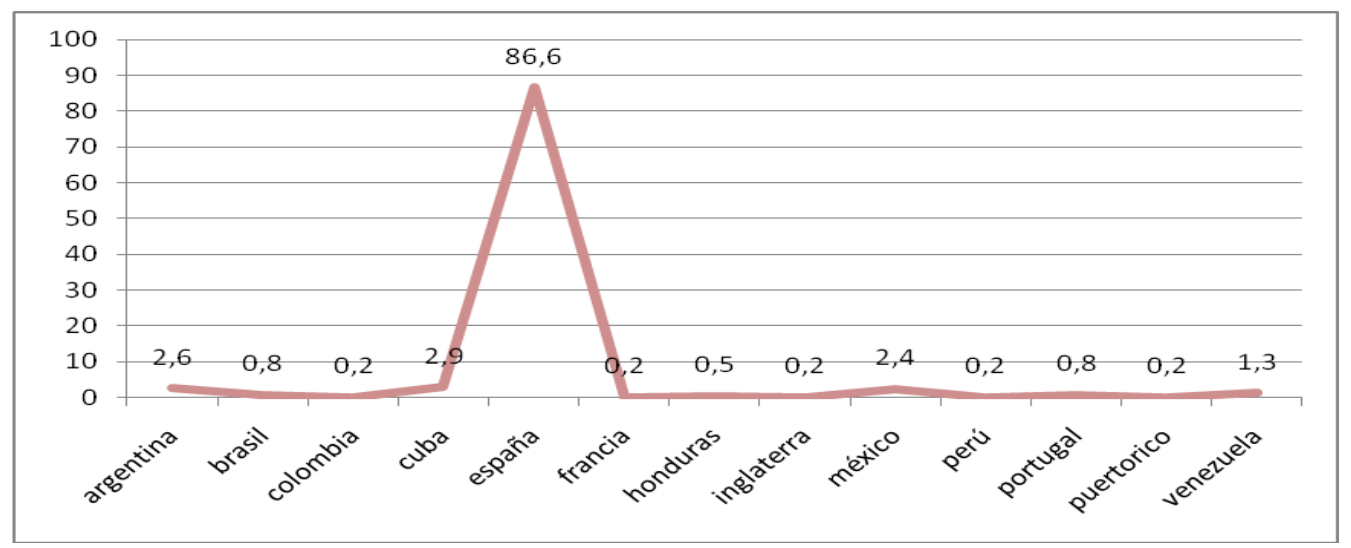

Puntualizando aún más los datos obtenidos, y atendiendo al país de procedencia (ver Gráfico 6), el 86.6\% son españolas, seguidas éstas muy de lejos por las cubanas (2.9\%), argentinas $(2.6 \%)$ y mexicanas $(2.4 \%)$. Los países menos representados son Venezuela $(1.3 \%)$, Honduras $(0.5 \%)$, Portugal $(0.8 \%)$ y Colombia, Francia, Inglaterra, Perú, Puerto Rico $(0.2 \%)$. Como vemos la presencia de artículos firmados por mujeres latinoamericanas es superior a las europeas, excluida España.

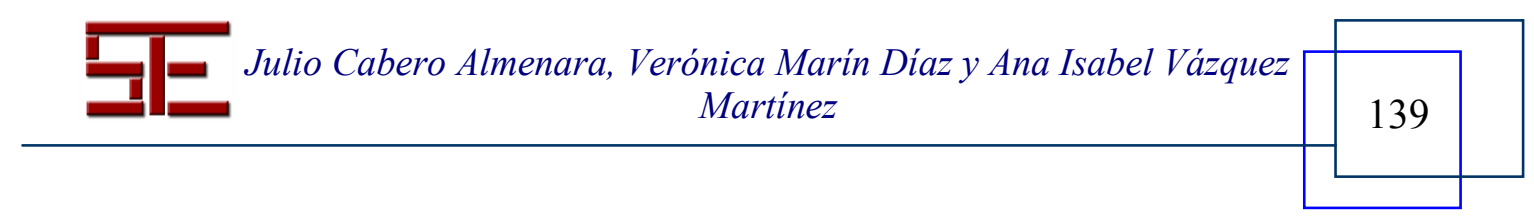




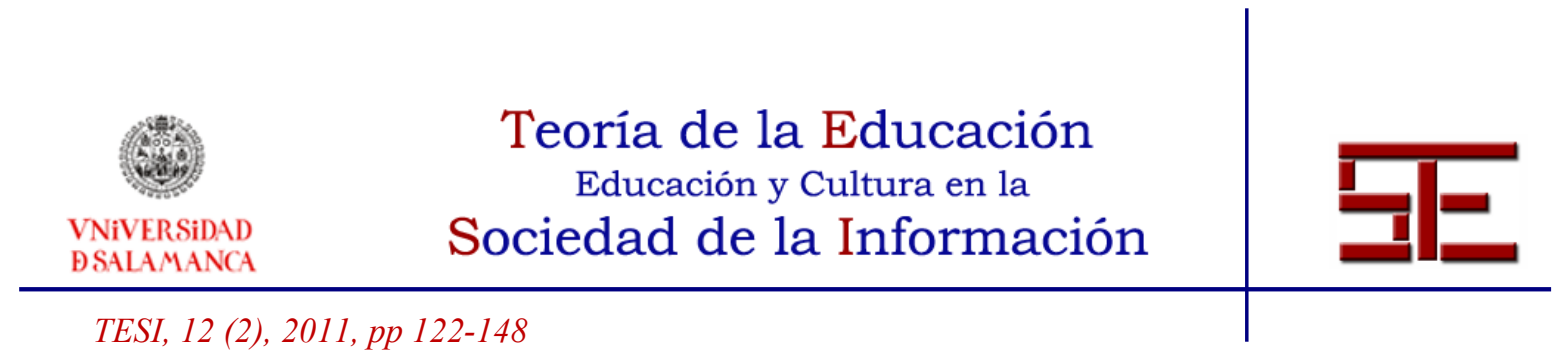

A continuación presentamos el estudio de la contingencia, que para nosotros es más significativa, la cual no es otra que la relativa al año de publicación y la del número de autoras. En el Gráfico 7, presentamos los resultados alcanzados.

Gráfico 7. Distribución total de las autoras por año

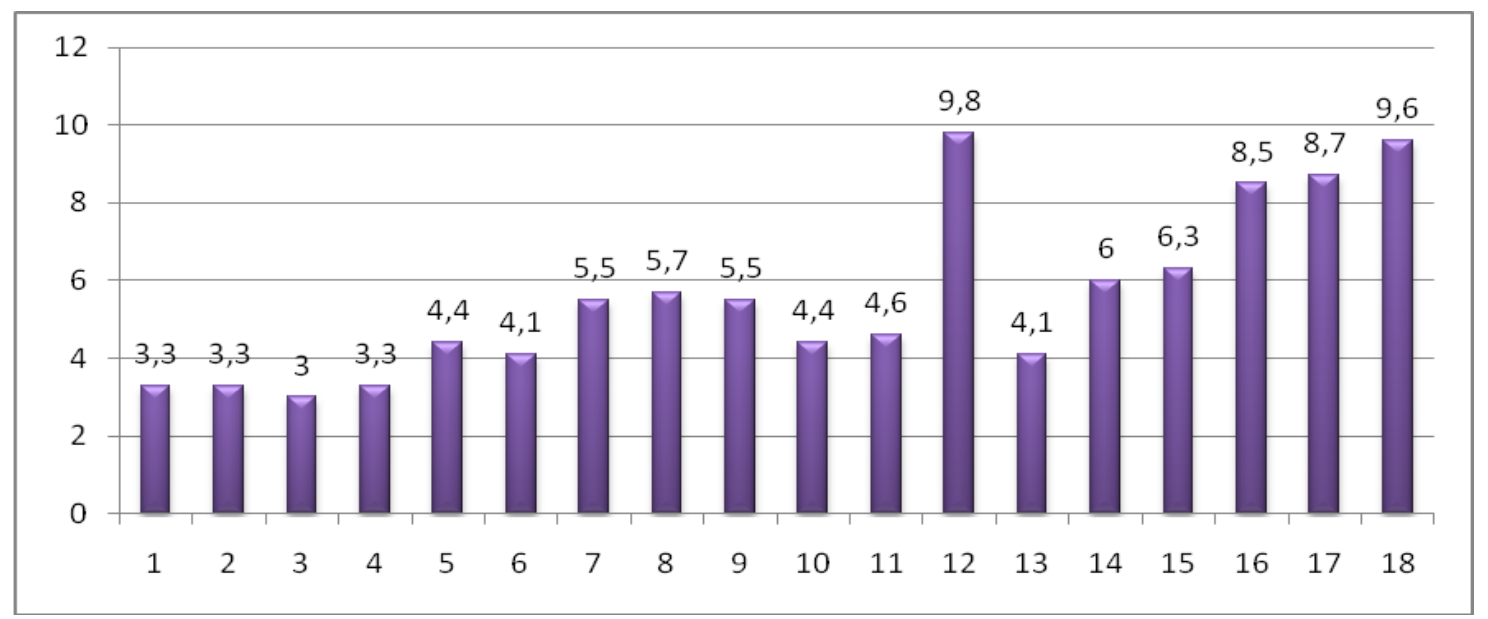

Como podemos ver 2005 es el año que más mujeres publican en Píxel-Bit (9.8\%), muy seguido de 2011 en el que lo hacen el 9.6\%. Los años 2010 y 2009 han supuesto también dos momentos de auge de participación femenina con una presencia de un $8.7 \%$ y un $8.5 \%$ respectivamente. Por el contrario, 1996 fue el año en que menos mujeres participaron en la firma de contribuciones, con tan solo una presencia del $3 \%$ frente a la presencia de autores masculinos, quienes han realizado el $38.8 \%$ de los artículos sin participación de mujeres y el $29 \%$ fue realizado por ambos de forma conjunta.

Por último, queremos hacer referencia a las temáticas que las autoras tocan en los artículos publicados. Como podemos ver en la Tabla 3 la distribución de frecuencias muestra que las temáticas más trabajadas han sido: Aplicación de las TIC en la Universidad con una presencia del 18.6\%, Reflexiones generales sobre las TIC (desigualdades, brecha digital, posibilidades, limitaciones, aspectos filosóficos ...) con un $12.7 \%$, Formación del profesorado con un 10.5\%, Teleformación/e-learning con un 9.1\% y Aplicación de las TIC en niveles no universitarios con un $8.6 \%$ de aparición, frente a temáticas relativas a la utilización de la Prensa, el Cine, los Medios de comunicación de masas, la Radio educativa, los Dibujos Animados, la Publicidad, la

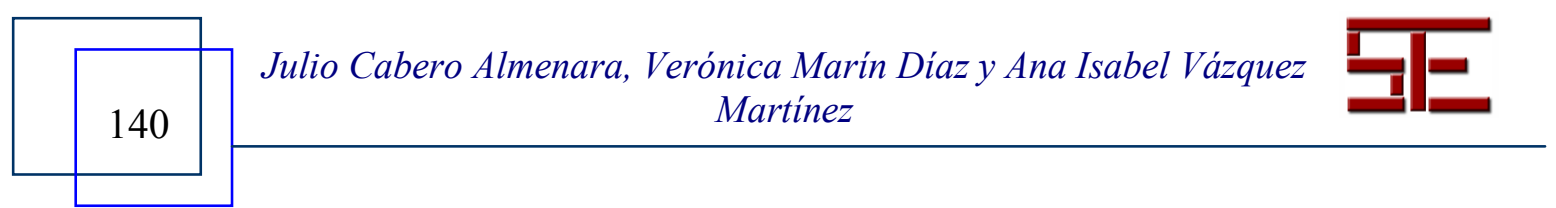




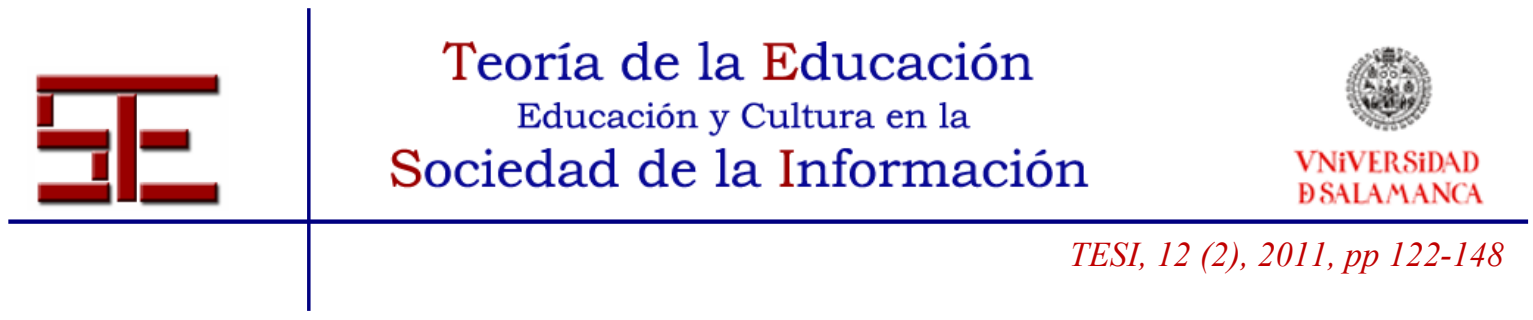

Fotografía/diapositiva, la Inteligencia Artificial y la Comunicación Audiovisual, que no han sido tratados en ninguno de los artículos en los que ha habido participación femenina, bien como autoras bien como coautoras.

Tabla 3. Temáticas tratadas por las autoras.

\begin{tabular}{l|c}
\multicolumn{1}{c}{ TEMÁTICAS } & $\%$ \\
\hline Investigación en medios y nuevas tecnologías & $5 \%$ \\
\hline Actitudes de los profesores hacia la tecnología & $5.5 \%$ \\
\hline Actitud del alumno hacia la tecnología & $2.7 \%$ \\
\hline Diseño de software informático & $1.4 \%$ \\
\hline Vídeo aplicado a la enseñanza & $1,8 \%$ \\
\hline Diseño de páginas web & $1.4 \%$ \\
\hline Diseño de materiales para la red & $3.6 \%$ \\
\hline Montajes audiovisuales/diaporamas & $0.5 \%$ \\
\hline Evaluación de medios y materiales de enseñanza & $5.5 \%$ \\
\hline Formación del profesorado & $10.5 \%$ \\
\hline Formación de los alumnos (alfabetización audiovisual) & $4.1 \%$ \\
\hline TIC y formación ocupacional & $1.4 \%$ \\
\hline Las TIC y la orientación & $0.9 \%$ \\
\hline Las TIC en la educación de adultos & $1.8 \%$ \\
\hline Plataformas de teleformación & $5.9 \%$ \\
\hline Las TIC aplicadas a la educación a distancia & $4.5 \%$ \\
\hline Enseñanza asistida por ordenador & $2.7 \%$ \\
\hline Teleformación/e-learning & $9.1 \%$ \\
\hline Utilización educativa de la red & $3.6 \%$ \\
\hline Tutoría on-line/ asesoramiento on-line & $2.3 \%$ \\
\hline Prensa & $0 \%$ \\
\hline Televisión & $1.4 \%$ \\
\hline Cine & $0 \%$ \\
\hline Medios de comunicación de masas & $0 \%$ \\
\hline Videoconferencia & $1.4 \%$ \\
\hline Radio educativa & $0 \%$ \\
\hline Material impreso/ Hábitos lectores & $1.4 \%$ \\
\hline Comic & $0.5 \%$ \\
\hline & \\
\hline & \\
\hline
\end{tabular}




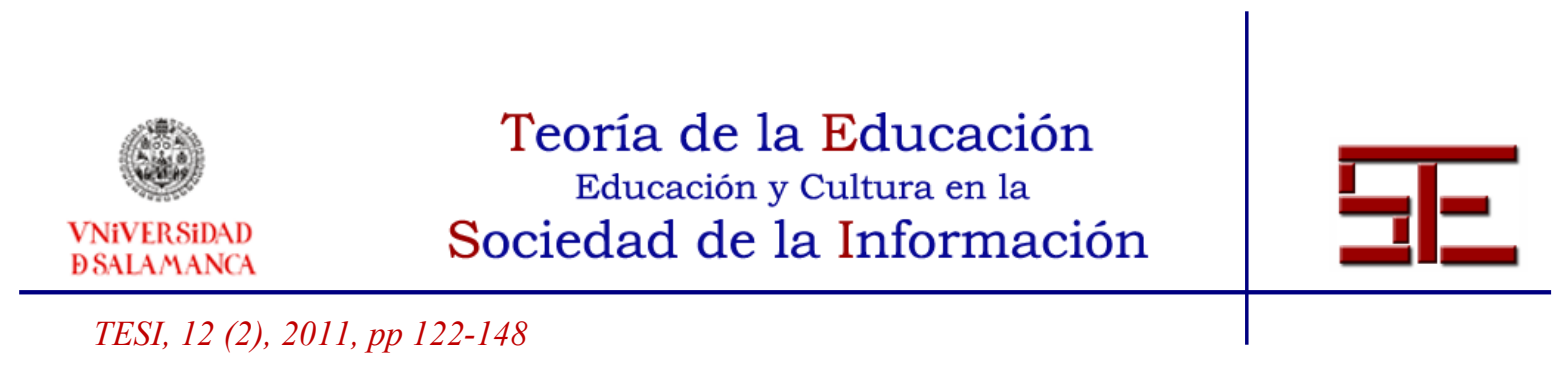

\begin{tabular}{|c|c|}
\hline TEMÁTICAS & $\%$ \\
\hline Dibujos animados & $0 \%$ \\
\hline Publicidad & $0 \%$ \\
\hline Fotografía/diapositiva & $0 \%$ \\
\hline Utilización de las TIC para la educación especial/diversidad & $6.8 \%$ \\
\hline Centro de recursos & $0.5 \%$ \\
\hline Las TIC y la organización/administración de los centros & $1.8 \%$ \\
\hline Trabajo colaborativo en redes & $3.2 \%$ \\
\hline Aplicación de las TIC en la Universidad & $18.6 \%$ \\
\hline Aplicación de las TIC en niveles no universitarios & $8.6 \%$ \\
\hline Experiencia de aplicaciones en contenidos curriculares concretos & $4.5 \%$ \\
\hline Experiencias educativas sobre audio/sonido & $0.5 \%$ \\
\hline Programas institucionales de implantación de las TIC & $0.5 \%$ \\
\hline $\begin{array}{l}\text { Reflexiones sobre la investigación en TIC y en tecnología educativa y en } \\
\text { tecnología educativa }\end{array}$ & $5 \%$ \\
\hline Aspectos cognitivos y TIC: estilos cognitivos, estilos de aprendizaje & $1.8 \%$ \\
\hline Planes de estudio referidos a las TIC & $0.5 \%$ \\
\hline Género y tecnología & $1.4 \%$ \\
\hline $\begin{array}{l}\text { Reflexiones generales sobre las TIC (desigualdades, brecha digital, } \\
\text { posibilidades, limitaciones, aspectos filosóficos, ...) }\end{array}$ & $12.7 \%$ \\
\hline Sociedad de la información/ Sociedad del conocimiento & $0.5 \%$ \\
\hline TIC y violencia & $0.9 \%$ \\
\hline Imágenes, estereotipos transmitidos por los medios & $0 \%$ \\
\hline Valores y TIC & $0 \%$ \\
\hline Informática aplicada a la educación & $1.4 \%$ \\
\hline Multimedia/hipermedia/hipertexto & $1.8 \%$ \\
\hline Inteligencia artificial & $0 \%$ \\
\hline Teletrabajo & $0.5 \%$ \\
\hline Videojuegos/ Juegos con ordenador & $2.7 \%$ \\
\hline Comunidades virtuales & $1.4 \%$ \\
\hline TIC y museos & $0.5 \%$ \\
\hline Las TIC en las empresa & $0.9 \%$ \\
\hline $\begin{array}{l}\text { Utilización de herramientas de con } \\
\text { Internet }\end{array}$ & $2.7 \%$ \\
\hline
\end{tabular}

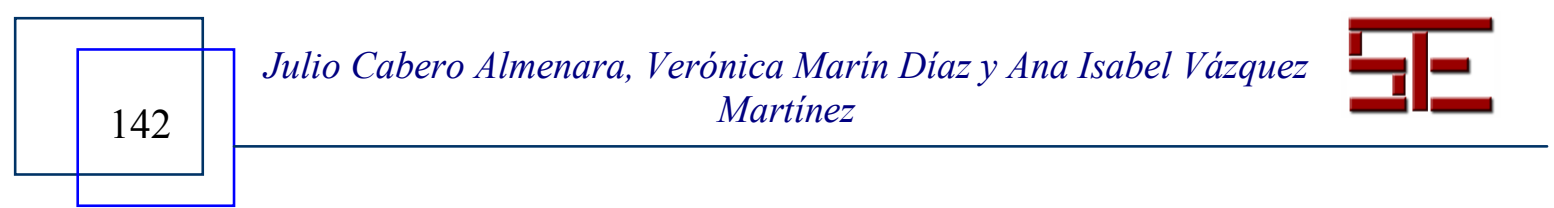




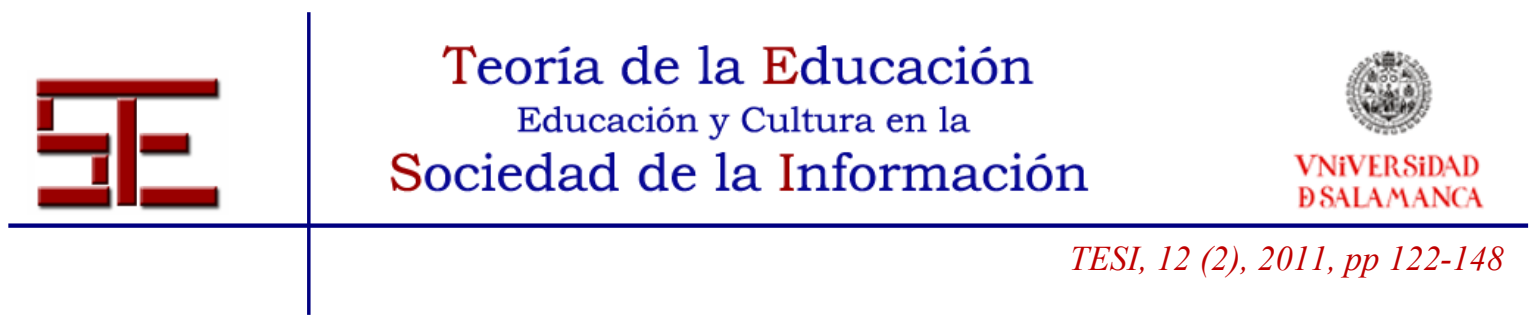

\begin{tabular}{l|c}
\multicolumn{1}{c|}{ TEMÁTICAS } & $\%$ \\
\hline La comunicación audiovisual & $0 \%$ \\
\hline Otros & $1.8 \%$
\end{tabular}

Presentados los resultados, pasaremos a ofrecer las conclusiones que nos permite nuestro estudio.

\section{4.- CONCLUSIONES}

El trabajo que hemos realizado nos permite obtener una serie de conclusiones, que vamos a señalar a continuación:

a) Ha existido una presencia en lo que se refiere a la publicación de artículos constante de autoras. Lo cual significa el interés que la temática de las TIC está despertando en nuestro contexto científico por las mujeres. Y ello es lógico si tenemos en cuenta la progresiva feminización que se está produciendo en las Facultades de Educación y de las personas que se dedican al terreno de las TIC.

b) Esta penetración es también constante, porque aunque han existido artículos publicados por las mismas autoras a lo largo de la historia de Píxel-Bit, la variabilidad ha sido amplia.

c) Los artículos publicados han sido firmados tanto por sólo mujeres como por mujeres y hombres. Aunque en porcentaje superan los artículos publicados sólo por hombres a los de sólo mujeres.

d) Los artículos que han realizado las mujeres son tanto de tipo teórico-conceptual como de investigación.

e) Hemos encontrado años, donde incluso el número de artículos firmados sólo por mujeres es mayor al firmado sólo por hombres.

f) No hemos encontrado ningún artículo que fuera coordinado o dirigidos por una mujer. Lo cual pudiéramos entenderlo como que los hombres siguen teniendo un papel más representativo en este tipo de acciones.

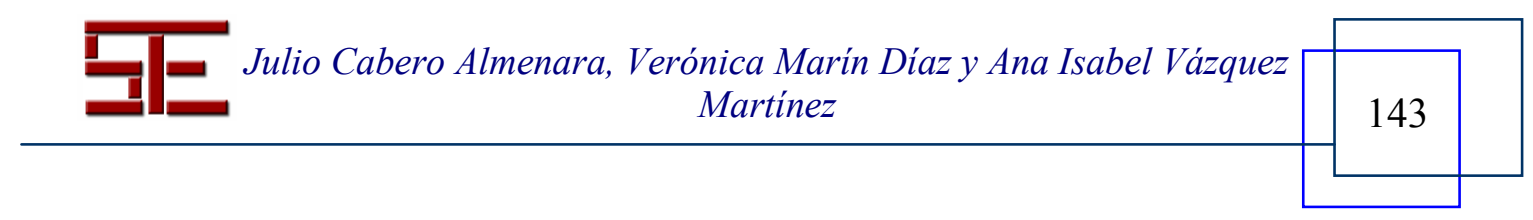




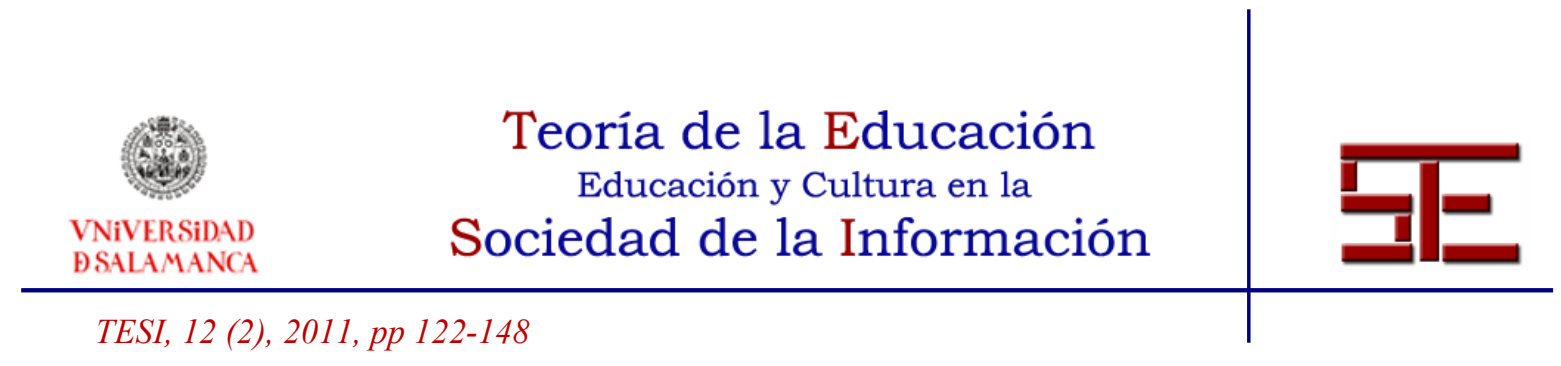

g) Y, por último, las autoras han presentado artículos que se incluían en todas las temáticas de la ficha que creamos para el análisis de los artículos. Si bien es lógico que algunas temáticas hayan sido más abordadas que otras, como las reflexiones generales sobre las TIC, la formación y el perfeccionamiento del profesorado, y la teleformación/e-learning.

Para finalizar, debemos señalar que nuestra investigación permite consolidar la ficha de análisis que ya elaboraron en su momento Cabero, Barroso y Llorente (2008) y que creemos que nos puede permitir contar con un instrumento de análisis de las temáticas de las publicaciones. Por otra parte, creemos que el estudio puede ser replicado en otras revistas de nuestro contexto científico centradas en las TIC.

\section{5.- BIBLIOGRAFÍA}

Abramo, G., D'Angelo, C. A. \& Caprasecca, A. (2009). Gender differences in research productivity: A bibliometric analysis of the Italian academic system. Scientometrics, 123. DOI: $10.1007 / \mathrm{s} 11192-007-2046-8$.

Agudo Arroyo, Y. (2006). El trabajo científico: dinámica, logros y reconocimiento. En García de Cortázar y Nebreda, M. L., Arranz Lozano, F., del Val Cid, C., Agudo Arroyo, Y., Viedma Rojas, Justo Suárez, C., Pardo Rubio, P. Mujeres y hombres en la ciencia española. Una investigación empírica (pp. 103-128). Madrid: Ministerio de Trabajo y Asuntos Sociales.

Almerich, G., Suárez, J. M., Orellana, N., Belloch, C., Bo, R. \& Gastaldo, I. (2004): Diferencias en los conocimientos de los recursos tecnológicos en profesores a partir del género, edad y tipo de centro. RELIEVE, 11 (2), 127-146. Extraído el 30 julio, 2009, de http://www.uv.es/RELIEVE/v11n2/RELIEVEv11n2_3.htm.

Anta Cebreros, C. (2006). Liderazgo de las publicaciones efectuadas por mujeres sobre las TIC en el área de Educación. Análisis comparativo de las publicaciones. III congreso online. Observatorio para la cibersociedad. Extraído el 16 enero, 2011, de http://www.cibersociedad.net/congres2006/gts/comunicacio.php?id=566.

Arranz Lozano, F. (2006). Actitudes y representaciones del personal investigador sobre la investigación científica. En García de Cortázar y Nebreda, M. L., Arranz Lozano, F., del Val Cid, C., Agudo Arroyo, Y., Viedma Rojas, Justo Suárez, C. Pardo Rubio, P.

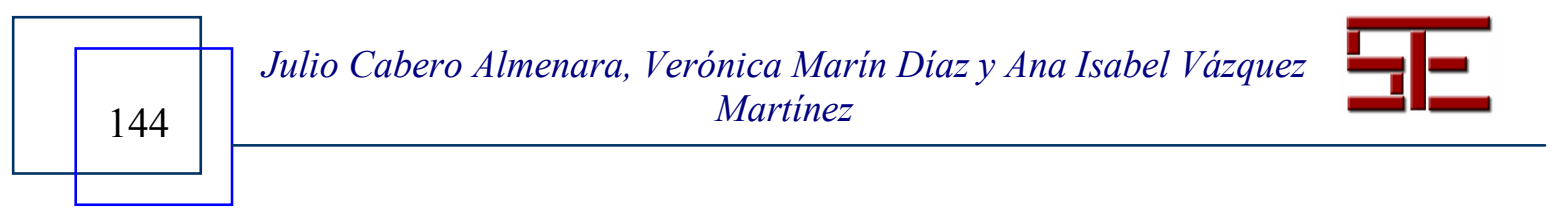




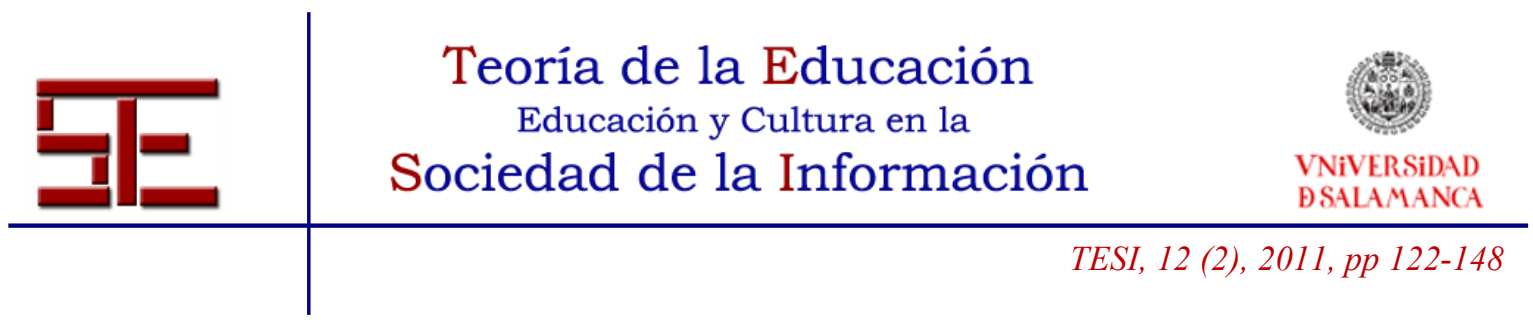

Mujeres y hombres en la ciencia española. Una investigación empírica (pp. 165-195). Madrid: Ministerio de Trabajo y Asuntos Sociales.

Bardin, L. (1986). Análisis de contenido. Madrid: Akal.

Barroso, J. \& Cabero, J. (2010). La investigación en Tecnología Educativa. Madrid: Síntesis.

Becker, C. (1986). Instructional uses of school computers. Reports from the 1985 national study. Baltimore, MD: Johns Hopkins University, Center for the Social Organization of Schools.

Cabero, J. (2004). Reflexiones sobre la brecha digital. En Soto, F. y Rodríguez, J. (Coords). Tecnología, educación y diversidad: retos y realidades de la inclusión digital. (pp. 23-42). Murcia: Consejería de Educación y Cultura.

Cabero, J. \& Loscertales, F. (1998). ¿Cómo nos ven los demás? La imagen del profesor y la enseñanza en los medios de comunicación social. Sevilla: Secretariado de Publicaciones de la Universidad de Sevilla.

Cabero, J., Barroso, J. \& Llorente, Ma C. (2008). EDUTEC. Plataforma de desarrollo de la tecnología educativa en Latinoamérica: un estudio a través de las aportaciones a sus congresos. EDUTEC, Revista Electrónica de Tecnología Educativa, 25. Extraído el 12 Noviembre, 2009, de http://edutec.rediris.es/Revelec2/Revelec25/Edutec25_Edutec_ plataforma\%20de\%20desarrollo_tecnologia_educativa.html.

Carles Romero, F. \& Ortega Rodríguez, J. (1999). La Representación de las Mujeres en las Revistas de Informática. Comunicación presentada al I Congreso de AUDEM (Asociación Universitaria de Estudios de las Mujeres): Los Estudios de las Mujeres y las Políticas Universitarias. Granada: Audem.

Castaño, C. (2005). Las mujeres y las tecnologías de la información. Internet y la trama de nuestra vida. Madrid: Alianza Editorial.

Castaño, C. \& González, A. M. (2008). La disparidad entre la participación y la posición de las mujeres en la investigación TIC: el caso del Plan Nacional I+D+i. Revista madri $+d, 21, \mathrm{n}^{\mathrm{o}}$ extraordinario, 118-126.

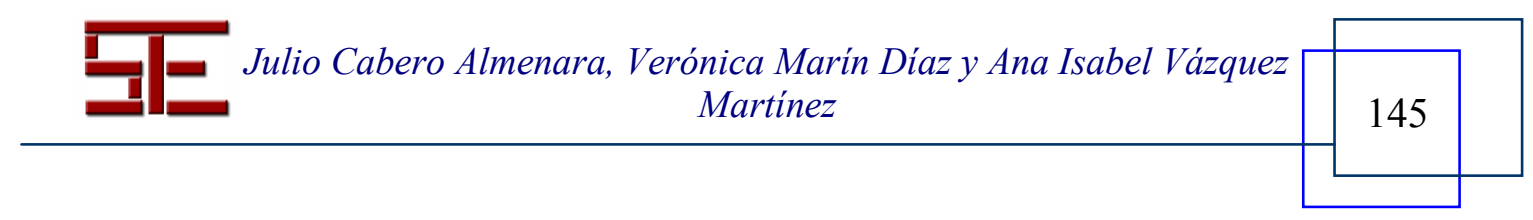




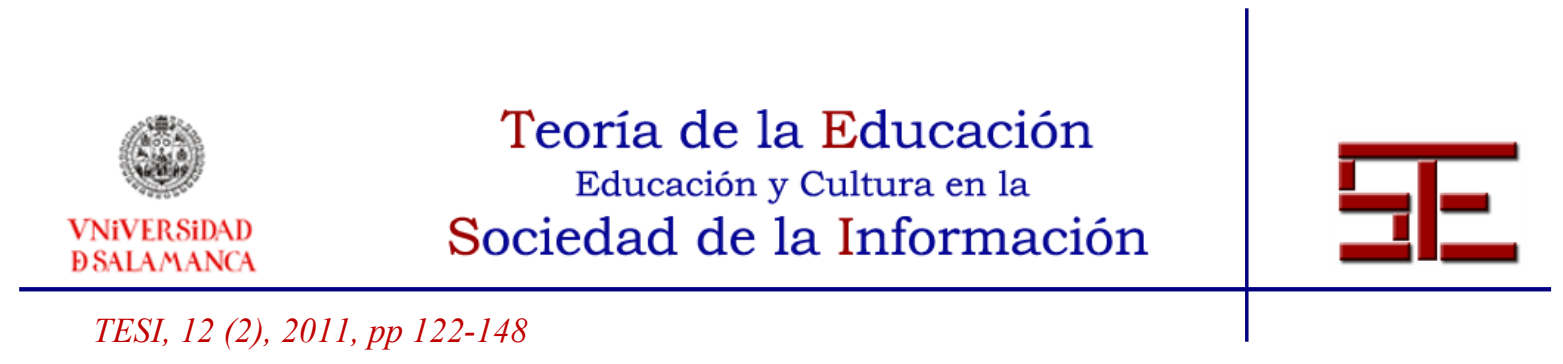

Fecyt (s.f.). La situación de las mujeres investigadoras en el sistema español de ciencia y tecnología. Madrid: Fecyt, $2^{\mathrm{a}}$ edición actualizada.

Fecyt (2006).Libro blanco de la investigación en Humanidades. Madrid: Fecyt.

Fletcher-Flinn, C.M. \& Suddendorf, T. (1996a). Computer attitudes, gender and exploratory behavior: a developmental study. Journal of Computing Research, 15 (4), 369-392.

- (1996b). Do computers affect 'the mind'?. Journal of Educational Computing Research, 15 (2), 97-112.

- (1997). Computers and 'the mind': an intervention study. Journal of Educational Computing Research, 17 (2), 103-118.

Fox, M. F. \& Stephan, P. E. (2001). Careers of young scientists: Preferences, prospects, and realities by gender and field. Social Studies of Science, 31, 109-122.

García de Cortázar, M. L. \& Nebreda, M. (2006). Imágenes de la profesión. En García de Cortázar y Nebreda, M. L., Arranz Lozano, F., del Val Cid, C., Agudo Arroyo, Y., Viedma Rojas, Justo Suárez, C., Pardo Rubio, P. Mujeres y hombres en la ciencia española. Una investigación empírica (pp. 135-148). Madrid: Ministerio de Trabajo y Asuntos Sociales.

Gargallo, B., Suárez, J. \& Belloch, M C. (2003). La división digital en el proceso de integración de las NTIC en la educación. Diferencias de género entre alumnos de E.S.O. de la comunidad valenciana. Teoría de la Educación. Educación y Cultura en la Sociedad de la Información, 4. Extraído el 1 diciembre, 2003, de http://www3.usal.es/ teoriaeducacion/DEFAULT.HTM.

Hernández Jorge, C. M., Acosta Jorge, M. C., Rodríguez Gutiérrez, E., González García, E. \& Borges Díaz, M. (2003). Uso de las TICs y percepción de la teleformación en alumnado universitario: una percepción diferencial en función del género y del ciclo de la carrera. Interactive educational multimedia, 7. Extraído el 5 de noviembre, 2003, de http://www.ub.es/ multimedia/ iem.

Krippendorff, K. (1990). Metodología del análisis de contenido. Teoría y práctica. Barcelona: Paidós de Comunicación.

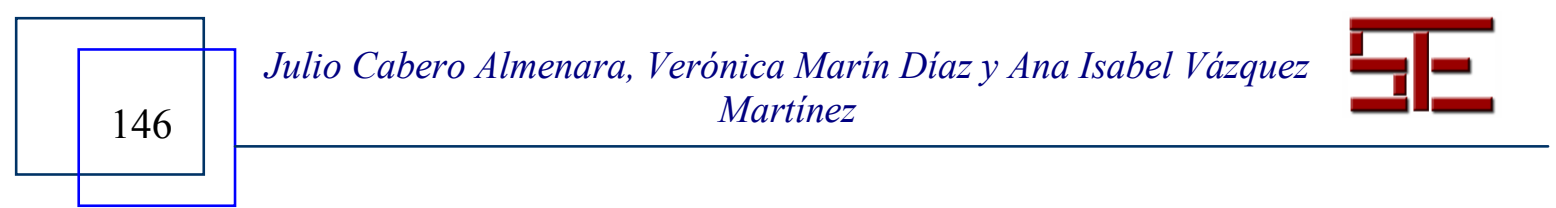




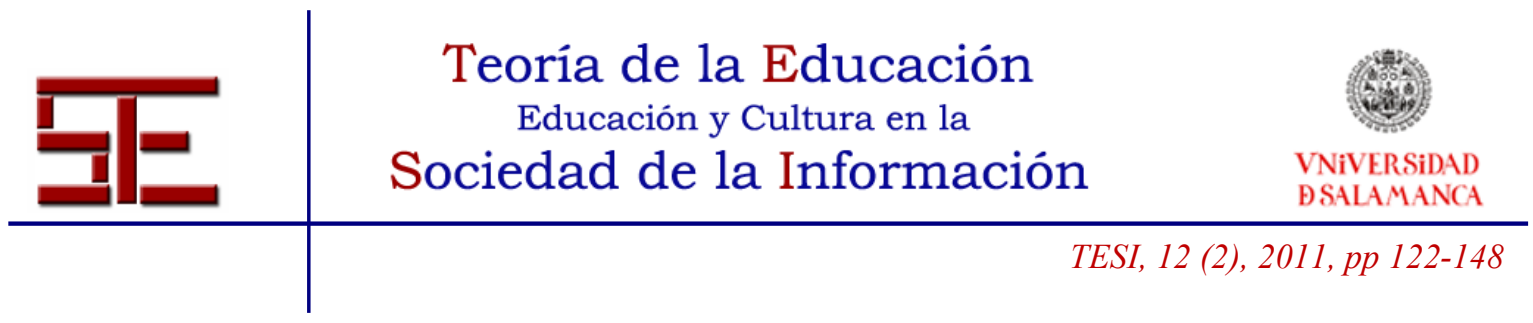

McGrath Cohoon, J., Nigai, S. \& Jofish ${ }^{\text {ee }}$ Kaye, J. (2010). Gender and Computing Conference Papers Author"s version, as submitted for publication. Extraído el 19 febrero, 2011, de http://www.ncwit.com/pdf/NCWITCohoon_confauthors2010.pdf.

Mallow, J.V. \& Hake, R. R. (2002). Gender Issues in Physics/Science Education (GIPSE) - Some Annotated References. Extraído el 15 noviembre, 2010, de http://www.luc.edu/depts/physics/mallow.html.

Nosek, B. A., Graham, J., Lindner, N. M., Kesebir, S., Hawkins, C.B., Hahn, Ch., Schmidt, K, Motyl, M. (s.f.). Cumulative and career-stage citation impact of socialpersonality psychology programs and their members. Extraído el 6 enero, 2011, de http://www.harzing.com/download/nosekpspb.pdf.

Orellana, N., Almerich, G., Belloch, C. \& Díaz, I. (2004). La actitud del profesorado ante las TIC. Un aspecto clave para la integración. Quinto encuentro internacional sobre educación, capacitación profesional y tecnologías de la información, Virtual educa. Extraído el 4 febrero, 2009, de http://www.virtualeduca.org.

Plomp, T. (1996). International encyclopedia of educational technology. Nueva York: Pergamon Press.

Romero Tena, R. (2004). Las docentes y su relación con las nuevas tecnologías. XXI, Revista de Educación, 6, 65-73.

Ruiz, J. \& Sánchez, J. (2010). El género como factor influyente en la estrategia para integrar las TIC en la práctica docente. Pixel-Bit, Revista de Medios y Educación, 37, 67-76.

Sandström, U. (2009). Combining curriculum vitae and bibliographic analysis: Mobility, gender, and research performance. Research Evaluation, 18, 135-142.

Sax, L. J., Hagedorn, L. S., Arredondo, M. \& Dicrisi, F. A. (2002). Faculty research productivity: Exploring the role of gender and family-related factors. Research in Higher Education, 43, 423-446.

Terlon, Cl. (1996). Las niñas y las nuevas tecnologías de la información. En Renée Clair (Ed.). La formación científica de las mujeres. ¿Por qué hay tan pocas científicas? (pp. 111-116). Madrid: Los Libros de la Catarata.

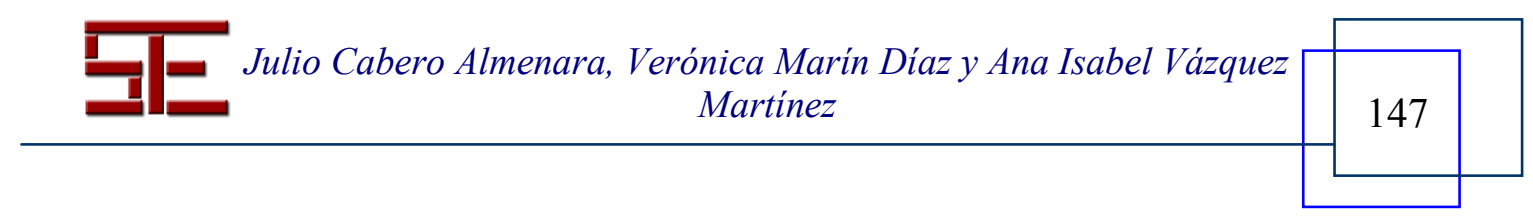




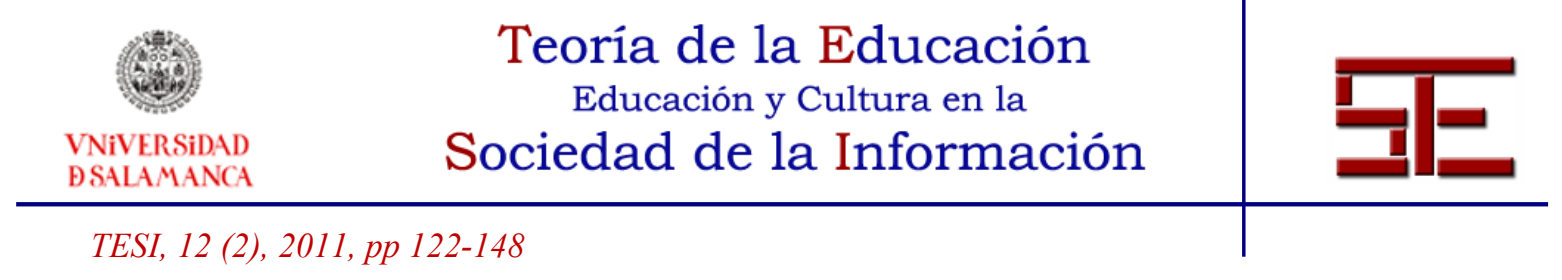

Urbina, S. (2002). Líneas de investigación sobre el uso del ordenador y educación infantil. Píxel-Bit. Revista de Medios y Educación, 19, 27-48.

Vázquez, R., Ángulo, F. \& Rodríguez, C. (2007). Las mujeres y el mundo de la computación y la informática. Píxel-Bit. Revista de Medios y Educación, 30, 31-40.

Viedma Rojas, A. (2006). Mujeres y hombres en I+D. Análisis de fuentes estadísticas oficiales. En García de Cortázar y Nebreda, M. L., Arranz Lozano, F., del Val Cid, C., Agudo Arroyo, Y., Viedma Rojas, Justo Suárez, C., Pardo Rubio, P. Mujeres y hombres en la ciencia española. Una investigación empírica (pp. 287-312). Madrid: Ministerio de Trabajo y Asuntos Sociales.

Waite, S. (2004). Tool for the job: a report of two surveys of information and communications technology traigning and use for literacy in primary schools in the west of England. Journal of Computer Assisted learning, 20, 11-20.

Wajcman, J. (2006). El tecnofeminismo. Madrid: Ediciones Cátedra, Universidad de Valencia, Instituto de la Mujer.

Xie, Y. \& Shauman, K .A. (1998). Sex differences in research productivity: New evidence about an old puzzle? American Sociological Review, 63, 847-870.

Para citar el presente artículo puede utilizar la siguiente referencia:

Cabero Almenara, J., Marín Díaz, V. y Vázquez Martínez, A. I. (2011). La mujer y la investigación en tecnología educativa. Análisis de su presencia en la autoría de artículos científicos, en Barrios Vicente, I. M. (Coord.) Mujeres y la sociedad de la Información. Revista Teoría de la Educación: Educación y Cultura en la Sociedad de la Información. Vol. 12, $\mathrm{n}^{\circ}$ 2. Universidad de Salamanca, pp. 122-148 [Fecha de consulta: dd/mm/aaaa]. http://campus.usal.es/ revistas_trabajo/index.php/revistatesi/article/view/8276/8280

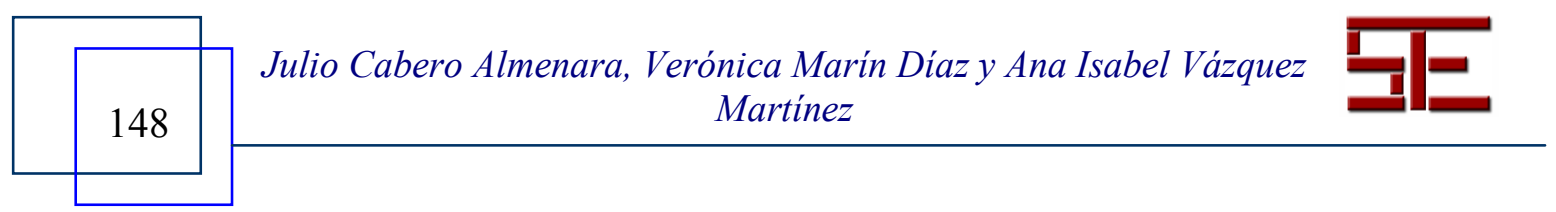

